\title{
Estructura ecológica principal del Chocó Biogeográfico según criterio de diversidad y singularidad de especies y ecosistemas
}

\section{Ecological principal structure of Chocó Biogeographic according to criterion of diversity and singularity of species and ecosystems}

\author{
Zulmary Valoyes ${ }^{1}$, Giovanny Ramírez ${ }^{2}$, William Klinger ${ }^{3}$, Fredy Carabalí ${ }^{4}$
}

\section{Resumen}

La estructura ecológica principal se define como un conjunto de elementos bióticos y abióticos que dan sustento a los procesos ecológicos esenciales de un territorio, cuya finalidad principal es la preservación, conservación, restauración, uso y manejo sostenible de los recursos naturales renovables, los cuales brindan la capacidad de soporte para el desarrollo socioeconómico de las poblaciones. Partiendo de este concepto se diseñó y construyó una estructura ecológica principal para la región del Chocó Biogeográfico, tomando en cuenta los componentes de biodiversidad y funcionalidad de los ecosistemas y servicios ecosistémicos. Dentro de cada uno de estos componentes se definieron criterios, y a su vez dentro de estos se establecieron subcriterios. Los resultados que aquí se publican corresponden al componente de biodiversidad y al criterio de diversidad y singularidad de especies y ecosistemas, para lo cual se trabajaron los subcriterios de riqueza y diversidad de especies, abundancia natural de especies particulares, riqueza y diversidad de ecosistemas, especies objeto de conservación (especies amenazadas, raras, endémicas y migratorias) y ecosistemas relictuales amenazados y singulares.

Palabras clave: Criterio de diversidad y singularidad de especies y ecosistemas, Ecosistemas estratégicos del Chocó Biogeográfico, Estructura ecológica, Subregiones ecogeográficas.

\begin{abstract}
Departing from this concept there was designed and constructed an ecological principal structure for the region of Chocó Biogeographic, taking in it counts the components of biodiversity and functionality of the ecosystems and services ecosistémicos, inside each of these components criteria were defined, and in turn inside these subcriteria were established. The results that here are published correspond to the component of biodiversity and to the criterion of diversity and singularity of species and ecosystems, for which they worked the subcriteria of wealth and diversity of species, natural abundance of particular species, wealth and diversity of ecosystems, species I object of conservation (threatened, rare, endemic and migratory species) and ecosystems relictuales threatened and singular
\end{abstract}

Keywords: Criterion of diversity and singularity of species and ecosystems, Ecological structure, Strategic ecosystems of the Chocó Biogeographic, Subregions echo geographical.
1 Bióloga, Especialista en Administración de Recursos Naturales, Estudiante de Maestría en Ciencias Ambientales, Investigadora contratista, Instituto de Investigaciones Ambientales del Pacífico, Quibdó, Colombia.

e-mail:zulmaryvaloyes@gmail.com

2 Biólogo, Magíster en Ciencias Biológicas, Investigador principal, componente Ecosistémico, Instituto de Investigaciones Ambientales del Pacífico, Quibdó, Colombia e-mail: gramirez@iiap.org.co

3 Ingeniero Forestal, Profesor Titular de la Universidad Distrital Francisco José de Caldas, Facultad de Medio Ambiente y Recursos Naturales, Grupo de Investigación PROPOBOS y Director del Instituto de Investigaciones Ambientales del Pacífico (IIAP), Quibdó, Colombia. e-mail: wklinger@iiap.org.co

4 Ingeniero Agrícola, Experto en SIG, Estudiante de maestría en Sistema de Gestión Agropecuaria, Investigador contratista, Instituto de Investigaciones Ambientales del Pacífico, Quibdó, Colombia. e-mail:frcaraba@gmail.com

Recibido: 2 de enero de 2012 Aceptado: 22 de mayo de 2012 


\section{Bioetnia Volumen 9 № 2 (julio-diciembre), 2012}

\section{Introducción}

El Chocó Biogeográfico es definido por Klinger et al. (2012) como «el conjunto de ecosistemas que comprende en forma longitudinal desde la provincia del Darién, al Este de Panamá, hasta el noroeste de Ecuador». Incluye, además, la región de Urabá, un tramo del litoral Caribe en el noroeste de Colombia y noreste de Panamá, y el valle medio del río Magdalena y sus afluentes Cauca-Nechí y San Jorge. Transversalmente, en la parte norte va desde las costas del mar Caribe hasta las del mar Pacífico. En Colombia y Ecuador va desde la costa pacífica y en forma irregular se interna a la parte andina de la cordillera occidental, aunque en gran parte de su recorrido de sur a norte toma como límite la divisoria de aguas de la misma. A pesar de que el Chocó Biogeográfico se percibe como un territorio homogéneo a escala regional, vale la pena resaltar que posee a nivel local una variedad de ecosistemas propios (manglares, ciénagas, bosques inundables, bosques secos, húmedos y nubosos, y páramo), enclaves de una diversidad específica particular que se enriquece por el recambio de especies a medida que se pasa de un ambiente a otro, contribuyendo así con la alta diversidad regional. Cubre $187.400 \mathrm{~km}^{2}$, con un terreno caracterizado por un mosaico de planicies fluvio-marinas, llanuras aluviales, valles estrechos y empinados y escarpes montañosos, hasta una altitud cerca de $4.000 \mathrm{msnm}$ en Colombia y más de 5.000 msnm en Ecuador.

El clima es de los más lluviosos del mundo y su punto más húmedo registra hasta $13.000 \mathrm{~mm}$ por año; en ningún punto de la región es menos de $3.000 \mathrm{~mm} /$ año. La alta pluviosidad, la condición tropical y su aislamiento (separación de la cuenca amazónica por la Cordillera de los Andes) han contribuido para hacer de la región Chocó Biogeográfico una de las más diversas del planeta: 9.000 especies de plantas vasculares, 200 de mamíferos, 600 de aves, 100 de reptiles y 120 de anfibios. Hay un alto nivel de endemismo: aproximadamente el $25 \%$ de las especies de plantas y animales de las registradas en Colombia.

Esta vasta región se encuentra ocupada sobre todo por poblaciones de etnias indígenas y afro que han desarrollado culturas caracterizadas por tener prácticas de intervención amigables con la naturaleza. Este es, tal vez, el principal factor de conservación de los ecosistemas que le conforman y que contienen gran abundancia de biodiversidad, considerados como estratégicos. Estas particularidades permiten que la toma de decisiones en materia de proyectos productivos y de infraestructura que puedan afectar la diversidad especificada y la particularidad ecosistémica de la región sean revisados concienzudamente para garantizar que su estructura ecológica se mantenga.

El presente documento muestra como resultado una descripción y representación geográfica de especies y ecosistemas seleccionados como prioridades de conservación, para lo cual se tuvieron en cuenta sitios con diversidad y singularidad de especies y ecosistemas.

\section{Métodos}

La selección de los ecosistemas estratégicos del Chocó Biogeográfico, seleccionados para ser incluidos dentro de la estructura ecológica, se seleccionaron de acuerdo con los parámetros tenidos en cuenta en el establecimiento de los criterios de selección por el equipo técnico del Ministerio de Ambiente, Vivienda y Desarrollo Territorial (MADS), Instituto de Hidrología, Meteorología y Estudios Ambientales de Colombia (IDEAM), Instituto de Investigaciones de Recursos Biológicos Alexander Von Humboldt (HUMBOLDT), Instituto Amazónico de Investigaciones Científicas (SINCHI), Instituto de Investigaciones Ambientales del Pacífico (IIAP), Instituto de Investigaciones Marinas y Costeras «José Benito Vives de Andreis (INVEMAR), Unidad Administrativa Especial del Sistema de Parques Nacionales Naturales (UESPIN); para la generación de los diferentes ejes temáticos de la estructura ecológica se utilizaron fuentes variadas, las cuales se citan a medida que se describe el criterio desde el componente al igual que el procedimiento espacial.

Generación de información de referencia. Basados en la información obtenida en diferentes fuentes bibliográficas existente en los diferentes planes de ordenamiento de cada una de las zonas referenciadas, así como las investigaciones desarrolladas por instituciones como el IIAP, Corporación Autónoma Regional del Cauca (CRC), Corporación Autónoma Regional de los Valles del Sinú y del San Jorge (CVS ), Corporación Autónoma Regional para el Desarrollo Sostenible del Chocó (CODECHOCO), Corporación Autónoma Regional del Valle del Cauca (CVC), Corporación Autónoma Regional de Nariño (CORPONARIÑO), Corporación Autónoma Regional del Centro de Antioquia (CORANTIOQUIA), universidades, Instituto Colombiano Agropecuario (ICA), Instituto Colombiano de Desarrollo Rural (INCODER), concejos comunitarios y resguardos indígenas, se seleccionaron diferentes ambientes que reunieran las características para ser incluidos dentro de la estructura principal del Chocó Biogeográfico; a partir de esta información se analizó y compiló el estado de conocimiento de cada una de las áreas .

Generación de información espacial. Para la generación de la información espacial correspondiente a los criterios de la estructura ecológica principal (EEP) del Chocó Biogeográfico Colombiano, se utilizó la información base a escala 1:100.000 suministrada por el Instituto Geográfico Agustín Codazzi en las llamadas Geo Data Base (IGAC GeoDataBase2008), en las cuales se encuentran presentes los ítems de superficies de agua (drenajes dobles-ríos, drenajes sencillos- 
quebradas, ciénagas, lagunas, embalses, bancos de arena, canales sencillos, islas, madresviejas y pantanos), relieve (curvas de nivel), administrativos (centros poblados), toponímicos (sitios orográficos), transporte aéreo y terrestre (carreteras vías fluviales y férreas). Partiendo del mapa de cuencas y subcuencas hidrográficas generadas por el IIAP, con la metodología propuesta por el IDEAM, se estimó la existencia de 8 grandes cuencas y 80 subcuencas y se hizo el cálculo de sus respectivas áreas en la proyección de MAGNA-SIRGAS, específicamente en el Sistema de Coordenadas Planas Magna Colombia Oeste.

En cuanto al criterio de diversidad y singularidad de especies y ecosistemas, en el cual describen las áreas actuales $\mathrm{y}$ potenciales que contienen alta riqueza y diversidad de especies, alta riqueza y diversidad de ecosistema, especies objeto de conservación (amenazadas, endémicas, raras, migratorias) y ecosistemas relictuales, amenazados y singulares, se colectó y generó la información espacial que se describe a continuación:

\section{Cartografía utilizada}

Geodatabase del IGAC a escala 1:100.000.

Límites municipales y nacionales de Colombia a escala $1: 100.000$.

- Mapas de referencia (América, República de Panamá y límite marítimo colombiano).

Manglares de la costa pacífica chocoana, generado por el IIAP en el año 2005.

- Manglares del mapa de ecosistemas continentales, marinos y costeros del IGAC e institutos.

- Manglares del Proyecto de Zonificación Ecológica del Pacífico Colombiano.

Otros estudios del IIAP.

Otros estudios de corporaciones regionales del Pacífico.

Procedimiento espacial

Selección de áreas de algunos municipios.

Digitalización de áreas específicas descritas y tomadas de los mapas de los informes.

Unificación de la proyección de mapas temáticos suministrados por los institutos.

- Interpretación del criterio por parte de un grupo profesional interdisciplinario.

- Se diagramó un mapa temático con escala fuente de dato de 1:100.000, en la mayoría de los casos y escala de impresión de 1:800.000 para poder visualizar el Chocó Biogeográfico en un tamaño de papel pliego de $90 \mathrm{~cm} \mathrm{x}$ $1,3 \mathrm{~m}$.

\section{Resultados}

Criterio de diversidad y singularidad de especies y ecosistemas. Para el diseño y selección de la estructura ecológica principal según el componente de diversidad y singularidad de especies y ecosistemas, se utilizaron los criterios que se describen a medida que se citan y comprenden (riqueza y diversidad de especies, abundancias naturales de especies particulares, riqueza y diversidad de ecosistemas, especies objeto de conservación, ecosistemas relictuales, amenazados y singulares. La estructura ecológica principal del Chocó Biogeográfico, teniendo en cuenta sus particularidades y el criterio para la selección de áreas que contengan diversidad y singularidad de especies y ecosistemas, está constituida por 36 áreas (Tabla 1).

Descripción de la estructura según el criterio de diversidad y singularidad de especies y ecosistemas. De acuerdo con los criterios establecidos, en el Chocó Biogeográfico existen áreas que contienen alta riqueza y diversidad de especies y por lo tanto deben ser incluidas en la estructura ecológica principal de esta región; las áreas se describen según el criterio.

Subcriterio riqueza y diversidad de especies. La estructura ecológica principal de la región del Chocó Biogeográfico según el subcriterio de diversidad y riqueza, debe incluir áreas naturales con altos índices de diversidad en cualquiera de los grupos biológicos presentes. Las áreas deben permitir la obtención de datos que se puedan evaluar a la hora de ser tenido en cuenta en el establecimiento de figuras de conservación potenciales para la conservación de especies (Figura 1). Un sitio con alta representatividad será para efectos de esta propuesta aquel donde se encuentra un gran número de elementos de la biodiversidad tanto a nivel ecosistémico como de especies. Teniendo en cuenta lo anterior se seleccionaron las siguientes áreas enmarcadas dentro de las regiones fitogeográficas propuestas por Poveda et al. 2004.

\section{Subregión ecogeográfica Darién Tacarcuna}

Poveda et al. (2004) definen esta subregión como una llanura aluvial con zonas estuarinas del norte del Pacífico, que se caracteriza por presentar un suelo de la planicie aluvial del piedemonte, que solo existe en esta zona del Chocó Biogeográfico, con una humedad moderada, se localiza sobre la cuenca baja del río Atrato, desde el límite norte del municipio de Vigía del Fuerte, donde empieza la influencia de suelo de tipo pantanoso de la planicie aluvial del piedemonte, hasta el Golfo de Urabá.

Cerro de Tacarcuna. Este ecosistema se incluyó en la estructura ecológica principal del Chocó Biogeográfico por elevada biodiversidad que sus bosques sustentan. En este cerro aún se conservan extensiones de selvas vírgenes, hacia las partes más altas, representados por Anacardium excelsum, Brosimun utile y bosques de Pseudolmedia laeviagata, en menor proporción selvas con Prioria copaifera y Carapa guianensis (Rangel, 2004). Su riqueza está sustentada por la presencia de 58 especies distribuidas en 42 géneros y 28 
Bioetnia Volumen 9 № 2 (julio-diciembre), 2012

Tabla 1

Áreas incluidas en la estructura ecológica principal del Chocó Biogeográfico según el criterio de diversidad y singularidad de especies

\begin{tabular}{|c|c|c|}
\hline Subcriterio & Subregión ecogeográfica & Área seleccionada \\
\hline \multirow{10}{*}{$\begin{array}{l}\text { Riqueza y diversidad } \\
\text { de especies }\end{array}$} & Darien Tacarcuna & Cerro de Tacarcuna \\
\hline & Bajo Atrato & Riosucio \\
\hline & Central Norte & Medio Atrato \\
\hline & & Tutugnendo \\
\hline & & Salero \\
\hline & & Cerro del Torrá \\
\hline & Baudó & Bosques del Golfo de Tribugá \\
\hline & & Alto Baudó \\
\hline & Litoral Pacífico & Delta del río San Juan \\
\hline & & Bajo Calima \\
\hline \multirow{7}{*}{$\begin{array}{l}\text { Abundancias naturales } \\
\text { de especies particulares }\end{array}$} & Litoral Pacífico & Manglares de la costa pacífica \\
\hline & Bajo Patía-Mira & Natales de Nariño \\
\hline & & Guandales de Campnosperma panamensis \\
\hline & & (Sajales) de Nariño \\
\hline & & Naidizales del río Patía \\
\hline & Bajo Atrato & Arracachales del Bajo Atrato \\
\hline & & Cativales de los ríos Atrato y León \\
\hline \multirow{3}{*}{$\begin{array}{l}\text { Alta riqueza y diversidad } \\
\text { de ecosistemas }\end{array}$} & Bajo Atrato & $\begin{array}{l}\text { Bajo Atrato (Riosucio, Carmen del Darién y } \\
\text { Belén de Bajirá) }\end{array}$ \\
\hline & Litoral del Pacífico & Parte baja del río San Juan \\
\hline & Patía-Mira & Deltas de los ríos Mira y Patía (Nariño) \\
\hline \multirow{6}{*}{$\begin{array}{l}\text { Especies objeto de } \\
\text { conservación (especies } \\
\text { amenazadas, endémicas, } \\
\text { raras) }\end{array}$} & Mulatos & Cerro Murrucucú \\
\hline & Central Norte & Quibdó \\
\hline & Tacarcuna - Darién & Cerro de Tacarcuna \\
\hline & Baudó & Alto Baudó \\
\hline & Barbacoas-Maguí & Barbacoas \\
\hline & Litoral Pacífico & Micay y Timbiquí \\
\hline \multirow{9}{*}{$\begin{array}{l}\text { Ecosistemas relictuales, } \\
\text { amenazados y } \\
\text { singulares }\end{array}$} & Mulatos & $\begin{array}{l}\text { Bosques húmedos tropicales relictuales de } \\
\text { Córdoba } \\
\text { Bosques subxerofíticos del Urabá antioqueño }\end{array}$ \\
\hline & Los Saltos & Bosques relictuales de Caoba (Swietenia \\
\hline & Central Sur & Bosques secos relictuales del Dagua \\
\hline & Litoral del Pacifico & Mangarles del Pacífico colombiano \\
\hline & Bajo Atrato & Sistemas cenagosos del Atrato \\
\hline & Bajo Atrato y Litoral del Pacífico & Ecosistemas de manglar \\
\hline & Bajo Patía-Mira & Bosques de Guandal \\
\hline & Central Norte & Cerro del Torra \\
\hline & Darién-Tacarcuna & Bahías de Trigana y Sapzurro \\
\hline
\end{tabular}


familias (IIAP y CODECHOCÓ, 2010); por otro lado Cárdenas-López (2003) reporta para un área adyacente la presencia de 127 familias, 428 géneros y 747 especies, aumentando la diversidad del área. Para la eco-región del Darién Chocó se reporta una alta diversidad en lo que respecta a la fauna, 127 especies de anfibios y 97 especies de reptiles, la familia más diversa, con 35 especies, seguido por la familia Iguanidae con 26 especies; de igual forma reportan 577 especies de aves, siendo Tyrannidae la familia más diversa, con 28 géneros y 60 especies. Según este criterio The Nature Conservancy (TNC, 2004) reporta la presencia de 169 especies de mamíferos, 533 aves, 99 reptiles, 78 anfibios y 50 peces. Por otro lado (CI 2008) registró 60 especies de anfibios, 20 de reptiles y 120 especies de aves para la zona.

\section{Subregión ecogeográfica del Bajo Atrato}

Definida por Poveda et al. (2004), como una llanura aluvial con zonas estuarinas del norte del Pacífico, que se caracteriza por presentar un suelo de la planicie aluvial del piedemonte, que solo existe en esta zona del Chocó Biogeográfico, con una humedad moderada, se localiza sobre la cuenca baja del río Atrato, desde el límite norte del municipio de Vigía del Fuerte, donde empieza la influencia de suelo de tipo pantanoso de la planicie aluvial del piedemonte, hasta el Golfo de Urabá.

Riosucio. El punto que corresponde al municipio de Riosucio se incluyó dentro de la estructura ecológica principal del Chocó Biogeográfico porque se constituye en su conjunto en una de las zonas del mundo con mayor biodiversidad de especies animales y vegetales, la región es de transcendental importancia en la conformación de la biota del país y del continente debido a que su territorio ha sido el puente de intercambio de elementos bióticos entre el norte y el sur del continente a través del istmo de Panamá. Por pertenecer al Darién, se constituye en una de las 17 áreas más críticas para la conservación que quedan en el mundo según el concepto desarrollado por Myers (1988).

Naciones Unidas (2008) reportan la presencia de 57 especies de aves de las 93 reportadas para Colombia; para el grupo de los anfibios reportan 15 especies agrupadas en 8 familias de las 18 reportadas para el país; en cuanto a los reptiles se reportaron 9 especies; en cuanto a los mamíferos reportan la presencia de 10 especies. De acuerdo con los datos obtenidos en el EOT (2001) del municipio de

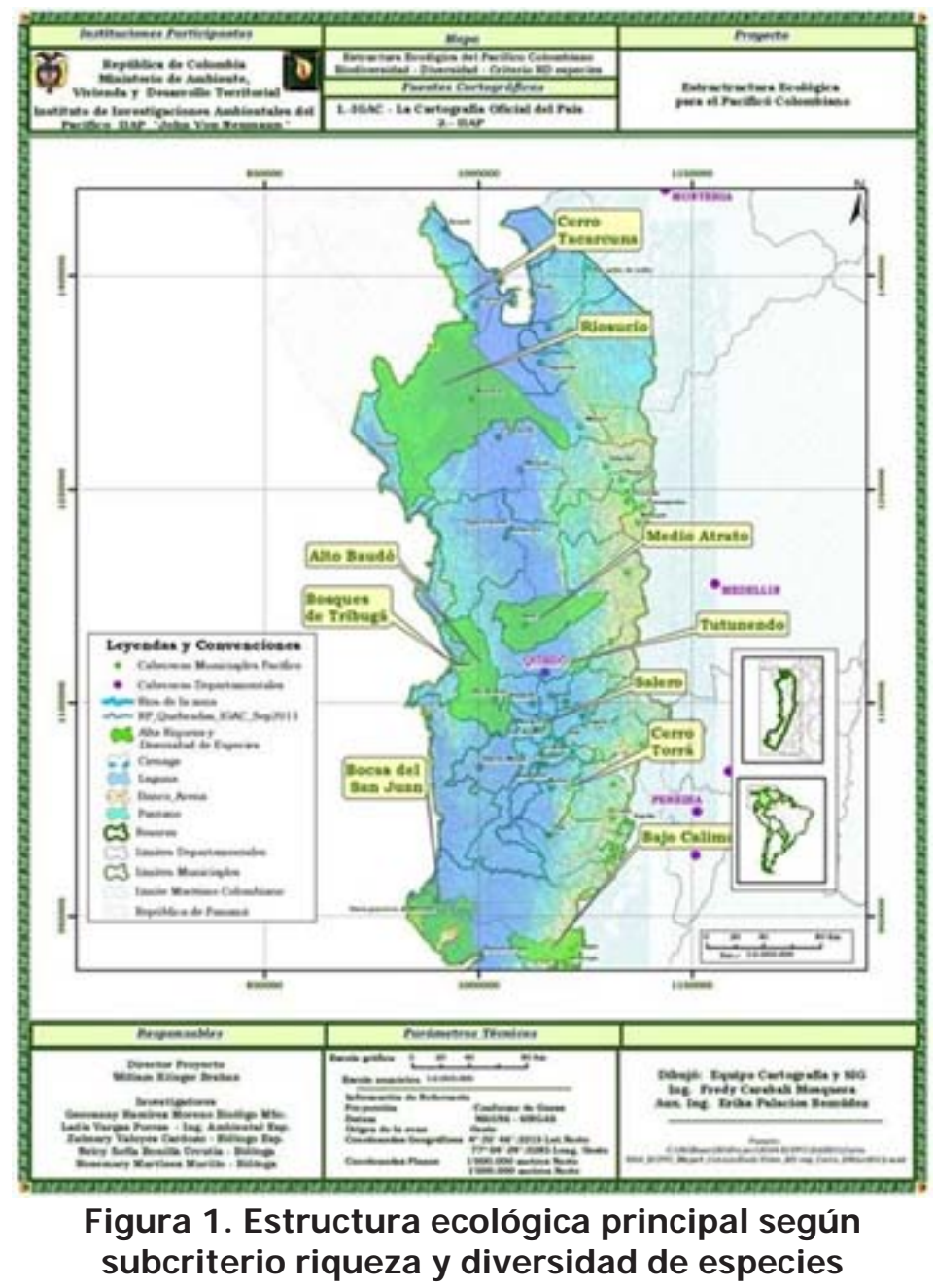

Riosucio (2001), para el área que corresponde al Darién chocoano se han registrado 3.493 plantas, esta cifra representa aproximadamente el $10 \%$ del total nacional; de igual forma se han registrado 433 especies de aves de las 1.815 reportadas para Colombia, lo que corresponde a $24 \%$ de la ornitofauna nacional; para el grupo de los anfibios se han identificado 129 especies que corresponden al $21 \%$ de las registradas en Colombia; para el grupo de los mamíferos se han registrado 218 especies que corresponden al $48 \%$ de las especies del ámbito nacional, sobresaliendo por su diversidad los murciélagos con $116(53 \%)$ especies, del total registrados para el área. El número de especies de reptiles identificadas en el área es de 170, de las cuales los escamosos (saurios y serpientes) representan el $90 \%$ aproximadamente. Al nivel de Colombia las 13 especies de cultura registrada para el área de estudio representan el 40,5\%, los saurios alcanzan el 27,3\% y las serpientes $43,3 \%$. La diversidad íctica del área de estudio es una de las más bajas en el país con 274 especies $(9,3 \%$ de la actual nacional) y coincide con la ocurrencia de un patrón de disminución paulatina de especies a medida que se avanza hacia el norte; de las especies registradas, la mayoría son dulceacuícolas primarias (165) y secundarias (26) que provienen de los ríos Atrato, Baudó y San Juan. 


\section{Bioetnia Volumen 9 № 2 (julio-diciembre), 2012}

Las demás especies (83) corresponden a peces marinos del golfo de Urabá.

\section{Subregión ecogeográfica central norte}

Corresponde al piedemonte y colinas bajas de la parte media norte del Pacífico; se caracteriza por presentar la mayor humedad disponible de todas las subregiones (perhúmedo a saturado) y con un tipo de roca sedimentaria transicional. Se extiende hasta la parte media oriental del municipio del Litoral del San Juan y comprende la totalidad de las cuencas altas de los ríos Atrato y San Juan (Poveda et al. 2004).

Medio Atrato. Esta área se incluyó en la estructura ecológica del Chocó Biogeográfico porque sustenta una gran riqueza biológica representada por una exuberante selva tropical, diversidad de flora y fauna, así como fuentes hídricas, enmarcadas en una serie de ciénagas, que representan para sus habitantes el sustento diario a través de actividades como la pesca, agricultura, etc. La flora del municipio del Medio Atrato está representada por 239 especies en 186 géneros y 67 familias; para el componente de fauna se han registrado 60 especies de aves pertenecientes a 13 órdenes y 25 familias, 377 individuos de herpetos distribuidos de la siguiente forma: 310 individuos de anfibios correspondientes a 18 especies incluidos en 9 familias; 67 individuos de reptiles, correspondientes a 15 especies incluidos en 9 familias para un total de 33 especies (IIAP y MAVDT, 2008).

Tutunendo. El punto corresponde al corregimiento de Tutunendo, perteneciente al municipio de Quibdó, hace parte de la estructura ecológica principal del Chocó Biogeográfico por su ubicación estratégica en el borde de la planicie central del Chocó, donde el inicio de la influencia de la cordillera Occidental y la fuerte incidencia de los factores climáticos (precipitación) sobre la vegetación, modelan la estructura y la composición del bosque (Gentry 1978). Tutunendo es reconocido por su alta riqueza florística considerado como el sitio del planeta con la mayor diversidad de árboles por $\mathrm{m}^{2}$, situación que se otorga gracias a la estrecha relación que existe entre la alta expresión de la biodiversidad y la precipitación excesiva de la zona; otra particularidad de la zona es la estrecha relación que tiene con la subregión de las tierras altas del Carmen de Atrato, que convierten a este sitio en una transición entre las dos biotas. Gentry (1993) manifiesta que esta área en términos florísticos presenta una gran riqueza y diversidad de especies; en un área de 0,1 ha se han reportado 262 especies de plantas con DAP $\geq 2,5 \mathrm{~cm}$, convirtiendo a la selva pluvial central en el área con mayor diversidad florística del Chocó Biogeográfico. Ramírez y Galeano (2011) reportan la presencia de 3.818 individuos de palmas en 1.5 ha pertenecientes a 18 géneros y 29 especies corroborando los altos índices de diversidad del área. Mejía y Pino (2009) reportan la presencia de 1.348 individuos de orquídeas distribuidas en 20 géneros y 49 especies. Rentería et al. (2007) registraron 207 individuos de reptiles distribuidos en 29 géneros y 39 especies. Cuesta et al. (2007) reportan la presencia de 21 mamíferos, 13 reptiles, 10 aves y 4 anfibios de uso alimenticio en la comunidad.

Salero. El punto corresponde al corregimiento de Salero, perteneciente al municipio Unión Panamericana; se incluyó en la estructura ecológica principal del Chocó Biogeográfico por presentar áreas boscosas estructural y funcionalmente recuperadas, dándoles la condición de bosques maduros, que presenta un alto índice de riqueza de flora como de fauna; el área presenta un relieve formado por los valles o planicies aluviales de los ríos, sobre todo en la llanura fluvial del San Juan, seguido de colinas y montañas asociadas con la prolongación de vertiente de la cordillera Occidental, posición geográfica que hace que esta área actué como corredor entre la biota de la llanura aluvial de los ríos Atrato y San Juan, y las estribaciones de la cordillera Occidental. Según este criterio Palacios et al. (2003) reportan para esta importante área la presencia de 1.347 individuos distribuidos en 50 familias, 139 géneros y 299 especies de plantas. De igual forma Grajales et al. (2003) reportan para la fauna datos de 2.730 individuos de escarabajos correspondientes a 13 géneros y 26 especies plenamente identificadas; para el grupo de los anfibios se registraron 199 individuos distribuidos en 5 familias, 9 géneros y 23 especies. Por su parte Machado et al. (2003) reportan para el grupo de las aves 250 individuos distribuidos en 11 familias, 26 géneros y 30 especies; la quirópterofauna (murciélagos) estuvo representada por 70 individuos, distribuidos en 2 familias, 5 subfamilias, 11 géneros y 19 especies (Jimémez et al. 2003) y el grupo de los escarabajos estuvo representado por 2730 individuos en 13 géneros y 23 especies (Neita et al. 2003). Lo anterior pone de manifiesto la alta riqueza de especies del área.

Cerro del Torrá. El punto que corresponde al cerro del Torrá se encuentra dentro de la estructura ecológica principal del Chocó Biogeográfico porque tiene la mayor diversidad florística por unidad de área en el mundo, posee ambientes con estructura florística distinta; su condición de bosque nublado hace que sea considerado como uno de los ecosistemas más singulares del mundo (FAO, 2002). Además el hecho de estar separado de la cordillera Occidental y su ubicación geográfica en el Chocó, convierte el área en una sitio de interés biogeográfico; los registros confirman la existencia de 468 especies de plantas vasculares distribuidas en 221 géneros y 90 familias (Silverstone-Sopkin y RamosPérez, 1995).

\section{Subregión ecogeográfica Baudó}

Poveda et al. (2004) incluyeron a esta zona en la subregión 
Estructura ecológica principal del Chocó Biogeográfico. Z. Valoyes, et al.

colinas y serranías del Baudó-Darién, la cual a su vez comprende tres subregiones, con suelos de formas aluviales y/o lacustres, húmedos de terraza. La subregión Baudó se caracteriza por el tipo de clima húmedo a muy húmedo y el tipo de roca sedimentario marino y se ubica en la Serranía del Baudó. Por la diversidad específica que sustenta fueron incluidas en esta el Golfo de Tribugá y el Alto Baudó.

Bosques del Golfo de Tribugá. El área correspondiente a los Bosques del Golfo de Tribugá se encuentra incluida en la estructura ecológica principal del Chocó Biogeográfico por sus altos índices de riqueza y diversidad de especies; el área hace parte de la Serranía del Baudó cubierta en su mayor parte de bosques poco disturbados. Según el sistema de Holdridge, el área corresponde a un bosque muy húmedo tropical (bmh-T) y bosque pluvial tropical (bp-T). En un estudio florístico realizado en el área, se estimó la abundancia, riqueza y diversidad de plantas leñosas en tres localidades de la región. En 1,8 ha, se reportaron 1.527 individuos donde se incluyeron plantas con un DAP $\geq 5$ y $10 \mathrm{~cm}$, las cuales se encontraron distribuidas en 52 familias, 136 géneros y 208 especies (Galeano 2002). Armbrecth y Armbrecth (1997) reportan para esta área 3.803 individuos de hormigas, agrupadas 4 subfamilias, 16 géneros y 25 morfoespecies. Mantilla y Jiménez (2006) ubican esta región como una de las áreas del Chocó-entro en donde se concentra el mayor número de quirópteros del Chocó Biogeográfico (92 especies). Mora et al. (2006) reportan una alta riqueza de Araceas en el área, la cual se encuentra sustentada por 114 especies nativas en 14 géneros; los géneros más grandes fueron Anthurium (38 especies) y Philodendron (36), los cuales comprendieron $65 \%$ del total de especies.

Alto Baudó. El área correspondiente al Alto Baudó se incluyó en la estructura ecológica principal del Chocó Biogeográfico, porque al ser una de las regiones más húmedas del mundo, la mayor parte del área se encuentra cubierta por bosques naturales, los cuales sustentan altos índices de diversidad de flora y fauna. Mosquera et al. (2007) registraron 1.618 individuos de plantas, representados en 257 especies, 156 géneros y 56 familias botánicas de los cuales 842 individuos, 161 especies, 108 géneros y 46 familias fueron encontrados en Pie de Pató, y 776 individuos, 161 especies, 98 géneros y 45 familias en Nauca (67 especies de este grupo). Robledo (2009) reportó 2.325 individuos, distribuidos en 166 especies pertenecientes a 38 familias en 5 ha. INVIAS y UTCH (2005) reportaron 45 especies para el grupo de los anfibios distribuidas en 17 géneros y 7 familias; el grupo de los reptiles está conformado por 28 especies, agrupadas en 20 géneros y 9 familias, las aves están representadas por 180 especies distribuidas en 140 géneros y 45 familias.

\section{Subregión ecogeográfica litoral Pacífico}

Definida por Poveda et al. (2004) como llanura aluvial con zonas estuarinas de la parte media del Pacífico. Se caracteriza por presentar una condición climática (humedad disponible) húmeda a muy húmeda, que es mayor que las otras dos subregiones; presenta además suelos de las formas aluviales y/o lacustres, húmedos de terrazas y de las formas litorales de origen marino. Se ubica desde el límite sur del municipio de Timbiquí (donde empieza a aumentar la humedad disponible), hasta el municipio de Bahía Solano.

Delta del río San Juan. El área correspondiente a los bosques del delta del río San Juan se incluyó en la estructura ecológica principal del Chocó Biogeográfico y sustenta altos índices de riqueza y diversidad de especies. Estudios florísticos realizados en el área por Cogollo y Jaramillo (2005), registraron 266 especies distribuidas en 126 géneros y 47 familias. BirdLife International (2011) manifiesta que esta área por pertenecer al sistema costero Pacífico, posee la mayor concentración de pelícanos (Pelecanus occidentalis); además, es un sitio importante para el descanso y la alimentación de otras aves marinas como piqueros, fragatas y cormoranes; se han observado concentraciones significativas de hasta cientos de individuos de chorlos, playeros y gaviotas migratorios.

Bajo Calima. El área correspondiente a los bosques del delta del río Bajo Calima cerca de Buenaventura (Valle del Cauca) se incluyó en la estructura ecológica principal del Chocó Biogeográfico porque posee una flora tropical con una alta diversidad de especies. Según este criterio Langendoen y Gentry (1991) reportan la presencia de 497 individuos de plantas distribuidos en 60 familias y 256 especies y manifiestan que esta área es uno de los sitios con mayores registros de plantas del planeta; en 0,1 ha se registraron más de 250 especies de árboles $\geq 10 \mathrm{~cm}$ de DAP. Una de las familias más representativas del área es Araceae, la cual presenta altos índices de diversidad, concentrada en las franjas con mayor precipitación en la transición entre las selvas de las tierras bajas y premontanas, hacia los $1.500 \mathrm{~m}$; los registros muestran la presencia de 11 géneros y 133 especies (Croat 1992).

\section{Subcriterio abundancias naturales de especies particulares}

La estructura ecológica principal de la región del Chocó Biogeográfico de acuerdo con este criterio debe incluir áreas naturales que contengan una concentración de especies particulares, que formen extensas áreas y que a su vez sean claves para el desarrollo y mantenimiento de una diversidad 


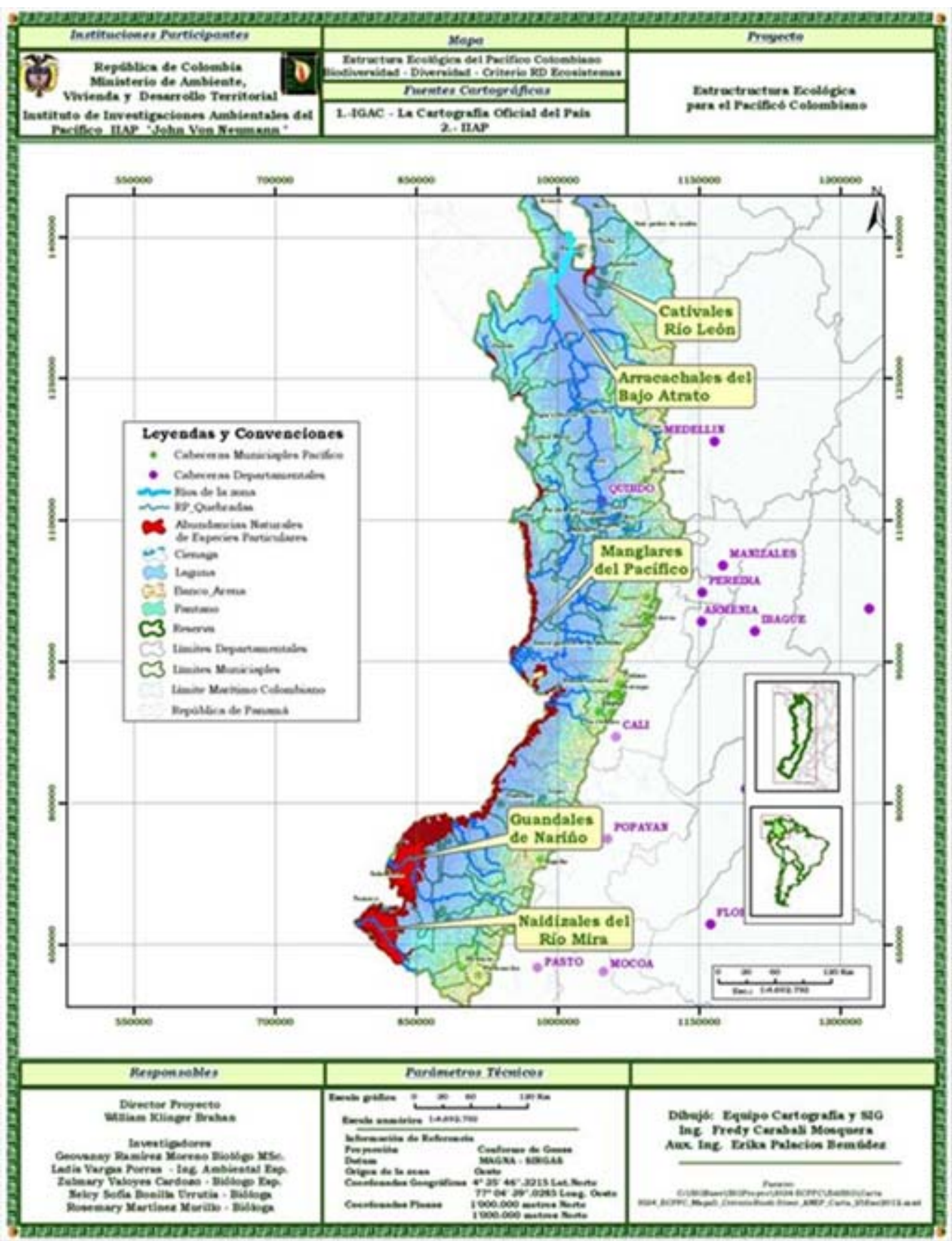

Figura 2. Estructura ecológica según subcriterio abundancias naturales de especies particulares.

de organismos que dependen de estas áreas para realizar sus procesos biológicos (Figura 2), en calidad de residente o visitante. Al mismo tiempo estas áreas se constituyen en fuente de desarrollo para las comunidades allí asentadas y dependen del manejo que esta les den para su permanencia.

\section{Subregión ecogeográfica litoral Pacífico}

Manglares de la costa pacífica. El área que corresponde a la franja de manglares que se extienden por toda la costa pacífica desde Bahía Solano hasta Santa Bárbara (Cauca), se incluyeron en la estructura ecológica principal del Chocó 
Biogeográfico por presentar una fuerte concentración de abundancias naturales de especies particulares, que abarcan unas 279.274 ha (Casas-Morroy, 2000), formando asociaciones de especies dominantes como Rhizophora mangle, $R$. harrisonii, R. racemosa, Avicennia germinans, Laguncularia racemos, Mora oleifera, Conocarpus erecta, Pelliciera rhizophorae, A. germinans y $R$. mangle, las especies más abundantes y las de mayor uso, seguidas por L. racemosa, $C$. erecta y $P$. rhizophorae (IAvH, 2011).

\section{Subregión ecogeográfica Bajo Patía-Mira}

Poveda et al. (2004) definen esta subregión como una llanura aluvial con zonas estuarinas del sur del Pacífico; comparte con la subregión Bajo Atrato las condiciones de humedad disponible y con la subregión Litoral Pacífico el tipo de suelo; presenta una marcada diferencia en cuanto a la humedad disponible. Se ubica al sur del Pacífico desde río Iscuadé (municipio de Santa Bárbara) hasta el río Mira (municipio de Tumaco).

Natales de Nariño. Los natales de Nariño y el Cauca se incluyeron en la estructura ecológica principal del Chocó Biogeográfico porque son ecosistemas que contienen una fuerte concentración de una especie en particular Mora megitosperma, la cual domina y modela la estructura del bosque donde crece, conforma bosque mixto con elementos típicos del manglar; en el sotobosque de estos ecosistemas aparecen otras especies como Pelliciera rhizophorae, Pterocarpus officinalis y Euterpe oleracera y se caracterizan por formar densas poblaciones (Rangel, 2004).

Guandales de Nariño (Campnosperma panamensis). El área que corresponde a los Guandales de Nariño debe quedar incluido en la estructura ecológica principal del Chocó Biogeográfico debido a la extensa superficie (75.000 hectáreas) que cubre Compnosperma panamensis. Esta región se considera como caso único en el mundo; esta asociación se encuentra distribuida desde la margen derecha del río Tapaje, extendiéndose hacia el suroeste por los ríos Tola, Satinga, Sanquinga, Patía y Patía el Viejo y terminando en el nacimiento del río Caunapí, sobre el municipio de Tumaco (Colorado 2011). Esta especie crece por lo regular formando masas coetáneas muy homogéneas, constituyendo en la mayoría de los casos más del $80 \%$ de la abundancia relativa por hectárea de estas asociaciones (Del Valle y Galeano, 1995), en estudios realizado se han contabilizado unos 5.000 árboles por ha de $10 \mathrm{~cm}$ y 1.500 árboles por ha de $20 \mathrm{~cm}$ (Del Valle 1996). Los bosques de C. panamensis, generalmente se encuentran asociados con Virola dixonii, Brosimum utile y $B$. alicastrum, en la costa pacífica colombiana se distribuyen en el Valle del Cauca, parte baja del río San Juan y Nariño (Rangel, 2004).
Naidizales de los ríos Patía. Los naidizales más extensos de Colombia se encuentran en el Pacífico sur, específicamente en el departamento de Nariño. Razón por la cual esta importante área debe ser incluida en la estructura ecológica principal del Chocó Biogeográfico. Euterpe oleoracea forma extensas áreas de bosque natural relativamente homogéneas. El naidizal se encuentra localizado detrás de los natales, más alejado de la influencia directa de las mareas, porque aunque soporta eventuales influencias de aguas salobres, se desarrolla mejor en suelos inundables con aguas dulces. No se sabe cuántas hectáreas comprendían los naidizales ni el grado exacto de su deforestación. En la actualidad es casi imposible estimar las existencias de naidí con las técnicas que han sido utilizadas para ello. Las imágenes de radar o fotografías aéreas no permiten desagregar fácilmente estos tipos de bosques de otros como el guandal. Aunque no se precisa el daño que han sufrido los naidizales de Nariño, de acuerdo con este criterio Cortés y Restrepo (2011) manifiestan que se estimaba que para finales de la década de 1970 el área de naidizal de la región era de 440.000 ha.

\section{Subregión ecogeográfica Bajo Atrato}

Arracachales del Bajo Atrato. Los arracachales del bajo Atrato se incluyeron en la estructura ecológica principal del Chocó Biogeográfico, debido a las extensas áreas de bosque natural que forman las poblaciones de esta especie en la planicie de la parte baja del río Atrato y en las orillas de sus tributarios, constituyéndose en el hábitat de especies residentes u ocasionales. Estas asociaciones se encuentran desde el Parque Nacional Natural los Katíos hasta el Golfo de Urabá, incluyendo las ciénagas de la ecorregión; se encuentra ampliamente distribuidos los matorrales denominados arracachales, estas forman y se ubican detrás de los manglares, hacia tierra adentro; esta asociación se desarrolla en ambientes que permanecen inundados por aguas dulces y salobres durante nueve meses al año; este ecosistema se encuentra dominado por Montrichardia arborescens. Desde el punto de vista ecológico los arracachales desempeñan un papel fundamental como hábitat y fuente de alimento para las especies que allí residen, debido a que forma densas poblaciones (Prieto et al. 2004).

Cativales de los ríos Atrato y León. Los cativales del bajo Atrato fueron incluidos en la estructura ecológica principal del Chocó Biogeográfico debido a las extensas áreas de bosque natural que forma la especie Prioria copaifera, la cual se desarrolla en las llanuras periódicamente inundables de los ríos Atrato y León, departamentos Chocó y Antioquia. Los cativales sobresalen por conformar comunidades de varias especies de árboles entre las que el cativo (P. copaifera) 


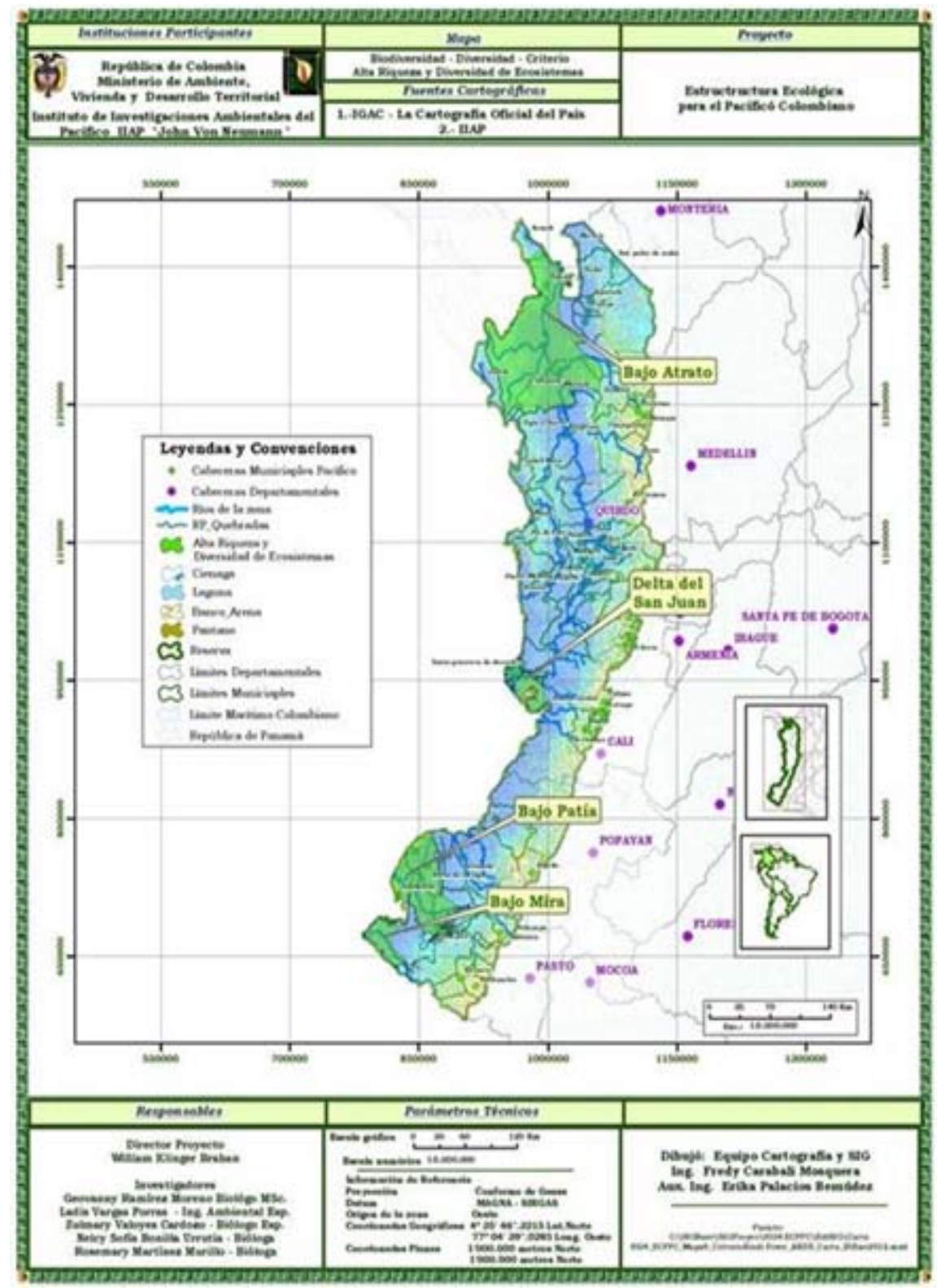

Figura 3. Estructura ecológica principal según subcriterio de
alta riqueza y diversidad de ecosistemas

es dominante (Giraldo y Del Valle, 2011). Esta asociación ha sido parcialmente aprovechada de manera selectiva mediante sistemas industriales y que en la actualidad han recupe-rado parte de su estructura, aunque han variado su composición específica y su biomasa, ocupando ahora el caracolí (Anacardium excelsum) las posiciones sociológicas de dominancia y emergencia. A pesar de lo anterior aún se conservan áreas extensas de esta asociación cuya extensión en el cálculo realizado por Linares (1988) alcanzó los $363.000 \mathrm{~h}$.

\section{Subcriterio de alta riqueza y diversidad de ecosistemas}

La estructura ecológica principal de la región del Chocó Biogeográfico teniendo en cuenta el criterio de riqueza y diversidad de ecosistemas debe incluir áreas claves que contienen diversidad de ecosistemas que pueden o no estar conectadas; cuando se conectan, se entrelazan de tal forma que uno sirve como flujo de energía del otro, albergando una diversidad de especies que necesitan del mantenimiento de estos para su supervivencia; la degradación de uno de estos ecosistemas perjudica de forma inmediata la estabilidad de las especies que se albergan o habitan en el área (Figura 3).

\section{Subregión ecogeográfica Bajo Atrato}

Bajo Atrato (Riosucio, Carmen del Darién y Belén de Bajirá). Debido a la diversidad de ecosistemas presentes en esta área, el Bajo Atrato debe ser incluido en la estructura ecológica del Chocó Biogeográfico. Esta importante área se localiza en el extremo noroccidental de Colombia y hace parte de la región Biogeográfica del Chocó, reconocida como una de las regiones con mayor diversidad del planeta; por su ubicación estratégica presenta una variedad de ecosistemas marinos y continentales. Comprende la zona de Urabá, el Parque Nacional de los Katíos, la cuenca baja del río Atrato y las cuencas altas de los ríos Salaquí y Juradó (Rangel 2004). Esta área se encuentra representada por los siguientes ecosistemas:

Manglares con especies como Avicennia germanis y Risophora ssp., (Risophora mangle, Pelliciera rhizophorae y Mora oleifera, Laguncunaria racemosa, Risophora sp. y Avicennia germanis, Pelliciera rhizophorae; en estos ecosistemas se forman asociaciones como los rodales conformados por Risophora y formando extensas áreas (Rangel 2004).

Llanura aluvial. Está conformada por las vegas bajas de los ríos Atrato y León, cuya característica especial consiste en presentar inundaciones permanentes o periódicas, que determinan 
áreas de subpaisajes o unidades de vegetación de acuerdo con el grado, frecuencia y duración de las inundaciones. Estas, a su vez, pueden subdividirse en categorías más específicas con base en su composición florísticas y grado de intervención (Rangel 2004).

Terrazas altas. La última etapa sucesional del catival se presentan en el piedemonte de las colinas. Están sustentadas por terrenos más firmes, con rasgos similares a los de la anterior unidad, pero donde el cativo empieza a afrontar una competencia más fuerte con especies de otras asociaciones, pues el anegamiento del terreno, factor que lo favorece, es ostensiblemente menor. Esto causa una regeneración natural más pobre, que se manifiesta en las especies que predominantemente emergen del dosel, entre ellas el caracolí (Anacardium excelsum), el sande (Brosimum utile) y el guasco (Eschweilera sp.). Estos terrenos, situados en condiciones de mejor drenaje y con una buena aptitud agrícola, han sido también foco de atracción para los colonizadores, por lo cual se encuentran altamente transformados

Bosques de terrazas planas ligeramente disectadas. En estos bosques de zonas más altas, el cativo (Prioria copaifera) desaparece completamente y otras especies como el sande (Brosimum utile) pasan a dominar ampliamente junto con otras especies como el caracolí (Anacardium excelsum), varias especies del género Iryanthera y el güipo (Cavanillesia platanifolia), entre otras. Ocupan zonas relativamente planas o ligeramente inclinadas, que están en ocasiones seccionadas por cañadas, casi siempre profundas y encajonadas.

Bosque de terrazas disectadas. Se caracteriza por su topografía sinuosa con presencia de numerosas y pequeñas elevaciones de poca pendiente, que están dispuestas dendríticamente. Es distintiva la presencia de algunas especies como el abarco (Cariniana pyriformis) y el güipo (Cavanillesia platanifolia), que presentan un alto desarrollo y gracias a la considerable altura que alcanzan cuando emergen sobre el dosel.

Región de colinas. Corresponde a una formación de bosque heterogéneo compuesto principalmente por el sande (Brosimum utile), que es la especie más abundante y por el abarco (Cariniana pyriformis), especie de alto valor comercial. Esta asociación es denominada comúnmente sandeabarco. Es un bosque cuya diversidad es mayor que la del catival y de acuerdo con su pendiente y altura sobre el nivel del mar, se divide en tres tipos bien diferenciados.

Bosque heterogéneo de colinas bajas. En las colinas bajas se pueden encontrar bosques altos o bajos que conforman asociaciones que no han sido suficientemente estudiadas y que involucran especies como abarco (Cariniana pyriformis), sande (Brosimum utile), guasco (Eschweilera sp.), caracolí (Anacardium excelsum), nuánamo (Iryanthera ulei), carrá (Huberodendrum patinoi), güipo (Cavanillesia platanifolia) y el guásimo (Apeiba aspera).
Bosque de colinas altas. En las colinas altas, los bosques están constituidos por árboles de porte mediano, siendo abundantes los Pouteria sp., los caimitos (Chrysophyllum sp.) y varias especies de palmas. Además, como consecuencia de frecuentes derrumbamientos, presentan abundantes claros en diferentes estados de sucesión. Las pendientes pronunciadas y las lluvias copiosas instauran suelos superficiales muy inestables y con escasa capacidad de soporte, lo cual explica el tamaño mediano de los árboles y la frecuente presencia de claros. Existen además bosques heterogéneos de colinas con pendientes mayores al 100\% que presentan una composición similar, sin embargo, el tamaño de los árboles se reduce y la ocurrencia de claros es mayor, conforman así una cobertura poco densa de vegetación baja achaparrada, poco uniforme y con alta presencia de palmas.

\section{Subregión ecogeográfica litoral del Pacífico}

Parte baja del río San Juan. Por la diversidad de ecosistemas presentes en esta área, el bajo San Juan hace parte de la estructura ecológica del Chocó Biogeográfico; por su ubicación estratégica presenta una variedad de ecosistemas marinos y continentales (Rangel 2004). La vegetación característica de esta subregión según los datos suministrados por Ramírez y Urrego (1999) se distribuye de la siguiente forma: vegetación de playa, Gynerium sagittatum asociada con Cecropia ssp. y Ficus ssp., entre otros. En la parte intermedia de la espiga, la vegetación está representada por Spondias mombin, Isertia pittieri, Cecropia sp., Ficus spp., Virola sebifera, Hibiscus tiliaceus y Gynerium sagittatum, Manicaria saccifera y Cocos nucifera. En general, la vegetación de playa trasera del delta del río San Juan pertenece a la zona de pantanos de agua dulce con substratos estables. Vegetación de transición: zonas posteriores a la unidad de playa trasera y anterior al manglar. Asociación característica de naidí (Euterpe cuatrecasana) y nato (Mora megistosperma). Vegetación de cordones litorales: se encuentran palmas como (E. cuatrecasana), (Socratea exorrhiza), (Manicaria saccifera), entre otras, asociadas con machares (Symphonia globulifera) y natos (M. megistosperma). Ramírezy Urrego (1999) reportan los siguientes ecosistemas:

Planicies fluvio-deltaicas. Ubicadas por fuera de la influencia mareal directa, pero inundables eventual o periódicamente por efectos del represamiento mareal. Morfológicamente estas zonas corresponden a superficies con gradientes topográficos bajos, cortados por canales fluviales principales y cubiertas por vegetación espesa de bosque tropical.

Llanuras intermareales. Sujetas a inundaciones y constituidas sobre todo por sedimentos finos (lodos y arcillas) con contenidos altos de materiales orgánicos. Morfológicamente estas zonas presentan superficies cóncavas con inclinaciones menores, densamente cubiertas, en condiciones de no inter- 


\section{Bioetnia Volumen 9 № 2 (julio-diciembre), 2012}

vención, por vegetación del ecosistema manglarino.

Depósitos arenosos litorales. Corresponden a terrenos inundables sólo esporádicamente, ubicados a lo largo de las líneas de la costa actuales o en el interior de las llanuras intermareales. La cobertura vegetal está compuesta por especies tolerantes a salinidades bajas.

Manglares. Aparecen en los planos intermareales protegidos de los canales estuarinos y esteros interiores asociados. Componen esta unidad para la zona, mangle rojo (Rhizophora mangle y $R$. harrissoni, e individuos híbridos de las dos), mangle comedero (Avicennia germinans), mangle fénix (Laguncularia racemosa), mangle piñuelo (Pelliciera rhizophorae) y nato (M. megistosperma).

Ecosistema del guandal de Campnosperma panamensis (sajales). Fisionomía: Los bosques prácticamente son rodales dominados por $C$. panamensis, a la cual se le asocian Virola dixonii, Brosimum utile y B. alicastrum (Rangel 2004).

\section{Subregión ecogeográfica Bajo Patía-Mira}

Deltas de los ríos Mira y Patía (Nariño). En el departamento de Nariño los principales ríos son el Patía y el Mira, que conforman los dos grandes deltas de la región. El Mira nace en la zona montañosa volcánica del noroeste y desemboca a la altura de la población de Milagros. El río Patía nace entre las cordilleras Central y Oriental, se forma por la confluencia de los ríos Timbío y Quilcacé. Se explaya en la llanura costera formando grandes meandros. Estos dos importantes ríos presentan una variedad de ecosistemas, razón por la cual deben ser incluidos en la estructura ecológica del Chocó Biogeográfico de acuerdo con los estudios realizados por (INVEMAR, CRC y CORPONARIÑO 2006) en el área se localizan los siguientes ecosistemas:

Montañas y colinas. Constituyen esta unidad geomorfológica las estribaciones occidentales de las colinas costeras y los remanentes rocosos de la erosión litoral. Tienen una topografía suave, cimas redondeadas, pendientes cortas y convexas y una red de drenaje con un patrón dendrítico, para el departamento del Cauca en el río Micay, entre Noanamito y la boca Naya, en Timbiquí y Guapí.

Valles aluviales. Se localizan paralelos a las vegas de estos ríos y están conformadas por depósitos aluviales finos que descansan sobre capas de cantos redondeados y gravilla. La red hidrográfica en el departamento del Cauca está conformada sobre todo por los ríos Guapí, Guajuí, Timbiquí, Bubuey, Saija, Micay y Naya. Son ríos con cauces relativamente cortos pero muy caudalosos debido a la alta pluviosidad. En el departamento de Nariño los principales ríos son el Patía y el Mira, que conforman los dos grandes deltas de la región.

Terrazas bajas. Ocurren a lo largo de los principales ríos de la zona, angostas terrazas aluviales del Pleistoceno con superficies ligeramente onduladas a planas, que ocupan una posición elevada con respecto al nivel actual de los ríos, por lo menos $5 \mathrm{~m}$. Se destacan Noanamito, Timbiquí y Guapí. En el departamento de Nariño no se observan muchas poblaciones en la zona costera que se localicen sobre terrazas, a excepción de Congal, en donde el agua se entra al pueblo sólo por un drenaje que está más bajo.

Abanicos aluviales. Su ubicación es en el piedemonte de las montañas y colinas y se originan como resultado de los procesos de remoción en masa o de erosión de las laderas y su posterior acumulación al pie de las mismas, donde hay un cambio brusco en la pendiente. Se han cartografiado abanicos aluviales importantes en Nariño, asociados con el curso medio del río Mira.

Pantanos de manglar. Corresponden a los terrenos localizados entre pleamar y bajamar, están constituidos por lodos con un alto contenido de materia orgánica de origen vegetal en su mayoría, aptos para el desarrollo de manglares y otras especies halófitas. Localmente dentro de esta geoforma se encuentran superficies que sobresalen topográficamente por encima del nivel de más alta marea 1 a $3 \mathrm{~m}$, denominadas promontorios arenosos aislados o «firmes». En el departamento del Cauca los pantanos de manglar se extienden en forma casi continua desde la boca del Naya hasta Guapi. Conforman franjas de anchura variable entre 2 y $5 \mathrm{~km}$, cortadas por una intrincada red de esteros que hacen parte de la misma unidad. En el departamento de Nariño los pantanos de manglar se localizan a lo largo de la línea de costa de la bahía de Tumaco o detrás de las islas barreras.

Pantanos de transición. Limitan hacia el mar con los pantanos de manglar y su delimitación es imprecisa porque está dada por los cambios graduales en los niveles de inundación, en la salinidad como consecuencia del poco alcance que tiene la marea en estos sectores, y por consiguiente en la vegetación que se sucede de forma paulatina. Son terrenos más secos con contenidos similares de arenas y lodos a los pantanos de manglar y también con un alto contenido de materia orgánica, por lo que también son utilizados para algunos cultivos. Paulatinamente pasan a tierra firme o a colinas y montañas. Conforman franjas de anchura variable detrás de los pantanos de manglar.

Firmes. Corresponden a superficies que sobresalen topográficamente por encima del nivel de más alta marea 1 a $3 \mathrm{~m}$; son promontorios arenosos con una geometría irregular y extensión variable de pocas decenas a centenas de metros. Son terrenos bien drenados, con facilidades de agua dulce, y aptos para la vivienda y la agricultura. Son el resultado de procesos de acreción litoral, con conformación de cordones litorales y a lo largo de los ríos y esteros de los diques naturales.

Islas barreras. Las islas barrera son barras arenosas elongadas en la dirección de la línea de costa y cuya altura 
Estructura ecológica principal del Chocó Biogeográfico. Z. Valoyes, et al.

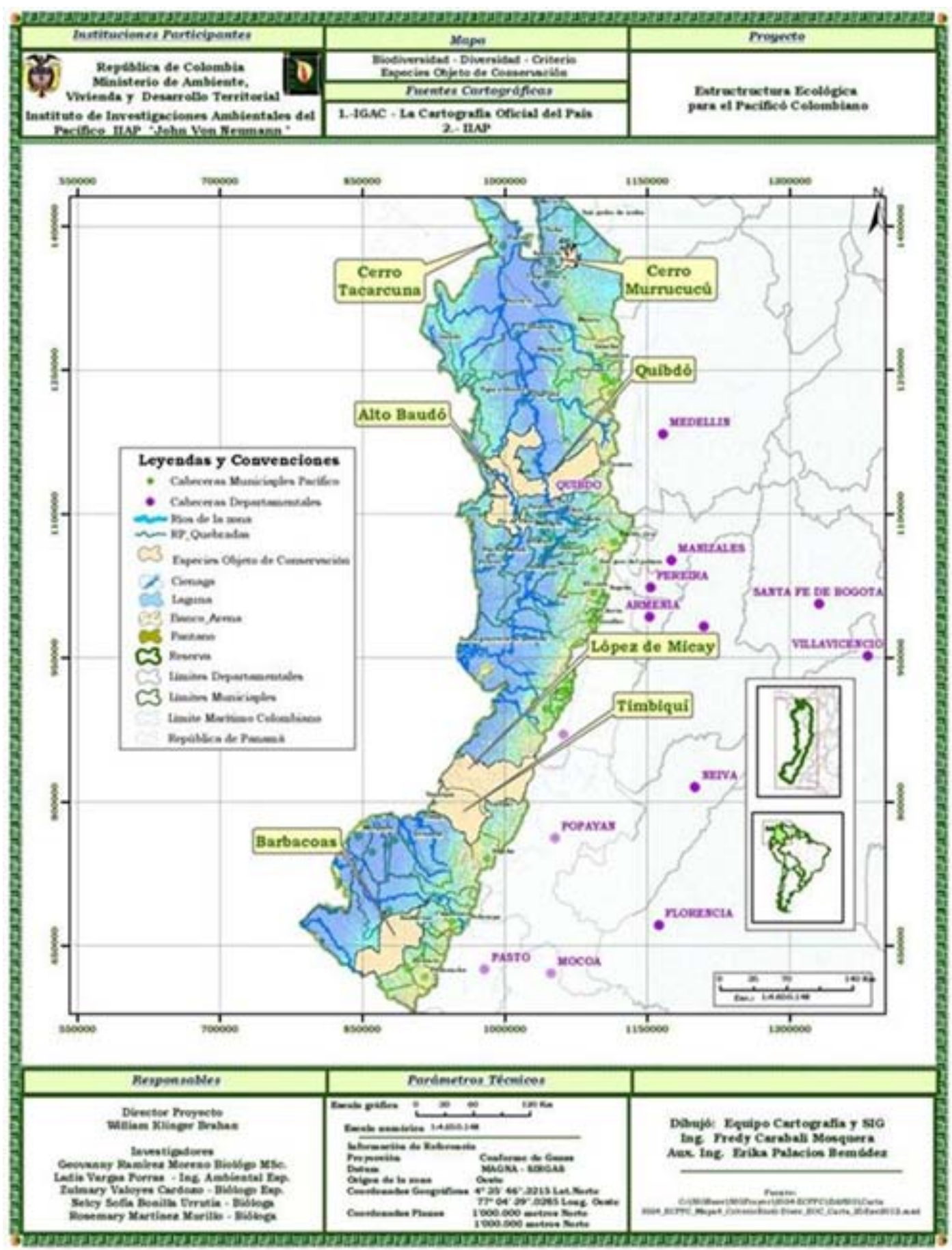

Figura 4. Estructura ecológica principal según subcriterio de especies objeto de
conservación (especies amenazadas, endémicas, raras)

está por encima de la línea de más alta marea, en donde se conforman bocanas de diverso tamaño. En el departamento del Cauca, el estuario de Micay, donde desemboca el río Naya y el Micay formando las bocanas de Santa Rita,
Monserrate y El Coco. En el departamento de Nariño, las playas están constituidas por arenas finas a medias, con abundantes ferromagnesianos que inclusive llegan a formar bancos de hasta un metro de espesor en la zona de berma. 


\section{Bioetnia Volumen 9 № 2 (julio-diciembre), 2012}

Bajos y llanuras intermareales. Las llanuras intermareales corresponden a los depósitos de arenas muy finas, finas y lodos que se extienden sobre la plataforma levemente inclinados al mar, en forma irregular, con canales de drenaje (caletas), elevaciones y depresiones elongadas y ondulitas (ripples) y son expuestos durante la marea baja y que por lo tanto fueron descritos también como playas, Su importancia geomorfológica radica en su gran extensión y en que hacen la función de disipadores de la energía del oleaje en especial en condiciones de tormenta.

\section{Subcriterio de especies objeto de conservación (especies amenazadas, endémicas, raras)}

La estructura ecológica principal de la región del Chocó Biogeográfico según el criterio objeto de conservación, debe incluir especies amenazadas, endémicas, raras o migratorias buscando la protección de este tipo de organismos, así como la conservación del hábitat donde estos residen porque tienen mayor prioridad de conservación que una especie que tenga sus poblaciones en buen estado y sea de amplia distribución. De acuerdo con los criterios establecidos las áreas que contienen especies objetos de conservación (Figura 4) y por lo tanto deben quedar en la estructura ecológica principal del Chocó Biogeográfico son:

\section{Subregión ecogeográfica. Colinas nororientales.}

Poveda et al. (2004), definen esta subregión como ambientes que corresponden a colinas y serranías cordilleranas de la parte norte del Pacífico; son dos pequeñas regiones con las mismas características ambientales pero interrumpidas geográficamente, que se caracterizan por tener un clima moderadamente húmedo. Se ubican al norte del Pacífico sobre las cabeceras de los ríos León y San Jorge (suroeste del municipio de Tierra Alta) y entre las cabeceras de los ríos Torquidató y Capá (municipios de Murindó y Lloró).

Cerro Murrucucú. Es el hábitat de una serie de organismos de flora y de fauna algunas endémicas de la región y otras que se encuentran bajo alguna categoría de amenaza según los listados de la UICN. Por las particularidades de esta área y la presión a las que han sido sometidas las especies que allí habitan debe ser incluida dentro de la estructura principal del Chocó Biogeográfico. Este ecosistema está localizado en Tierralta, Córdoba y contiene los últimos bastiones de bosques naturales del departamento, soporta una serie de especies endémicas de flora y de fauna, algunas de estas bajo alguna categoría de amenaza según la UICN. Entre las especies endémicas podemos mencionar: Corytophanes cristatus, Hernandia didymantha (VU) Dendrobates truncatus, Saguinus oedipus y Crax Alberti (Proaves, 2008; CVS, CONIF 2008). Según los reportes suministrados por la
(CVS 2006), las especies amenazadas presentes en el área y su categoría de amenaza equivalen a: Cariniana pyriformis (CR), Chigua restrepoi (CR), Cavanillesia platanifolia(VU), Lecythis tuyrana (VU), Licania silvae (VU), Magnolia sambuensis (VU), Wettinia hirsuta (VU), Cyathea andina (VU), Cedrela odorata (VU), Guarea cartaguenya (VU), Huberodendron patinoi, (EN), Guatteria tonduzzi (VU) Gustavia superba (VU) Pentaclethra macroloba (VU), Simarouba amara (VU), Dialium guianensis (VU), Jacaranda copaia (VU); especies como Astronium graveolens, Peltogyne purpurea, Caryocar amygdaliferum, Copaifera camibar y Brosimum utile, han soportado una gran presión por sus maderas lo que las tiene al borde de la extinción a nivel local y están seriamente amenazadas, Hymenaea courbaril, Astronium graveolens, Podocarpus oleifolius, Manilkara bidentata (CVS 2006).

\section{Subregión ecogeográfica central norte}

Quibdó. El punto corresponde a Quibdó, presenta características particulares en términos climáticos como altas precipitaciones, altas temperaturas, terrenos planos y quebrados. Esta área se encuentra al lado del piedemonte cordillerano, lo que hace que la flora y la fauna que aquí reside sea similar a la de otros lugares de tierras bajas, al mismo tiempo se pueden encontrar particularidades; los factores mencionados antes favorecen la presencia de una serie de especies endémicas del Chocó Biogeográfico o con algún grado de amenaza lo que hace necesario la inclusión del área en la estructura ecológica principal de la región; la fauna endémica se encuentra representada por Hyalinobatrachium aureoguttatum, Hyla rubracyla, Phyllobates aurotaenia, Colostethus pratti y la flora por Aiphanes acaulis (CR), A. macroloba, Wettinia oxycarpa, W. quinaria, Guzmania breviscapa, Pitcairnia barrigae, Compsoneura cuatrecasasii, Sloanea cabitensis, S. calva, S. chocoensis, S. esmeraldana, S. garcia-cossioi, S. loquitoi, S. pacuritana, S. pseudogranulosa, Dipteryx oleífera, Eschweilera neei, Gustavia petiolata, Cedrela odorata (EN), Iryanthera megistophylla, Virola dixonii, Peperomia densifolia, Piper certeguiense, $P$. corei, $P$. pedunculatum, $P$. perpusillum, $P$. sp.nov. (Tutunendo), P. tenuilimbum, Zamia pyrophylla, Mauritiella macroclada, Wettinia quinaria, Huberodendron patinoi (CR), Matisia bullata, M. racemifera, Phragmotheca lemniscata, Guzmania breviscapa, Licania calvescens, L. chocoensis (Galeano y Bernal 2005, Betancur y García 2006, Cárdenas y Salinas 2007, Ramírez et al. 2011) .

\section{Subregión ecogeográfica Tacarcuna-Darién}

Cerro de Tacarcuna. Alberga una fuerte concentración de endemismos y de especies con algún grado de amenaza; la 
presión que han sufrido los bosques que circundan, convirtiendo a Tacarcuna en un refugio de fauna y flora, razones por las que esta área debe hacer parte de la estructura ecológica principal del Chocó Biogeográfico. La ubicación estratégica convierte a esta área del Darién en el paso obligado de la biota que viene de norte y centro América hacia sur América; el cerro de Tacarcuna se eleva a $2.000 \mathrm{msnm}$. En este centro de endemismos, se encuentran varias especies de área restringida; se estima que hay alrededor de 30 especies de plantas, así como aves y mamíferos. Algunas especies fáunicas restringidas son: Xenornis setifrons Chapman (género endémico) Odontophorus dialeucos Wetmore conocida en tres localidades: Cerro Tacarcuna, Malí y Barrigonal. Oxyruncus cristatus tacarcunae Bangs y Barbour, Glyphorynchus spirurus spallidulus Peters, Chlorospingus tacarcunae Griscon, Syndactyla subalaris tacarcunae (Hernández 1992).

\section{Subregión ecogeográfica Baudó}

Alto Baudó. El área correspondiente al Alto Baudó debe ser incluida en la estructura ecológica principal del Chocó Biogeográfico porque presenta características físicas y biológicas que le proporcionan al área condiciones que la convierten en una de las regiones más húmedas del mundo, presenta bosques naturales que en las últimas décadas han estado sometidos a una fuerte presión antrópica como la extracción de madera, expansión de la frontera agrícola entre otras, las cuales han causado que un considerable número de especies de flora hoy se encuentren listadas en los libros rojos de Colombia con diferentes categorías de amenaza. Robledo (2009), ratificado por Cárdenas y Salinas (2007) y Klinger et al. (2011), revelan la presencia de 26 especies con algún grado de amenaza: Anacardium excelsum (NT), Tapirira myrianthus (EN), Annona muricata (EN), Aspidosperma cf. Oblongum (EN), A. cruentum (EN), Bombacopsis quinatum (EN), Huberodendron patinoi (VU), Ceiba pentandra (EN), Dcryodes acutipyrena (VU), Hymenaea oblongifolia (NT), Calophyllum longifolium (VU), Anibas perutilis (CR), Ocotea cernua (VU), Aniba sp. (VU), Ocotea cooperi (EN), Eschwilera sclerophylla(NT), Dugandiodendron mahechae (EN), Dugandiodendron magnifolia (EN), Cedrela odolata (EN), Sweitenia macrophylla (CR), Carapa guianensis (EN), Pentaclethra macroloba (VU), Brosimum utile (VU), Minquartia guianensis (CR), Andira inermis (VU), Vitex columbiensis (VU).

\section{Subregión ecogeográfica Barbacoas-Maguí}

Poveda et al. (2044) la definen como ambientes de piedemonte y colinas bajas del sur del Pacífico; presenta convergencias ambientales con la subregión central norte. Se ubica al sur del Pacífico desde río Timbiquí hasta el límite norte del municipio de Ricaurte.

Barbacoas. El alto grado de endemismos, la presencia de especies raras y amenazadas hacen de la reserva el Pangan un área con características particulares razón por la cual se incluyó en la estructura ecológica principal del Chocó Biogeográfico. El Pangan está ubicada en el piedemonte de la vertiente Pacífica de la Cordillera Occidental de los Andes en el municipio de Barbacoas, Nariño, en las estribaciones de la llanura occidental del Nudo de los Pastos; abarca un área de 352.365 ha de bosque primario húmedo tropical y súper húmedo premontano ubicadas entre los 550 y $1.900 \mathrm{~m}$, en las laderas orientales del valle del río Nambí. Su extensión incluye bosques primarios a lo largo del gradiente altitudinal de 620-1.700 m, incluyendo un tramo (10 ha) de bosque secundario de 15 años de edad a $650 \mathrm{~m}$ (Palacios y Constantino 2006).

El Pangan cuenta con altos niveles de endemismo y una alta riqueza de especies. Hasta la fecha se han registrado 48 especies de aves endémicas y 21 especies de aves amenazadas, lo que constituye la mayor concentración de aves endémicas del mundo. También posee una alta diversidad de herpetos, plantas e invertebrados, encontrándose en la reserva importantes poblaciones de especies amenazadas como Dendrobates histrionicus y Tremarctos ornatus. En esta área se encontraron 94 especies de lepidópteros representadas por 7 familias (Nymphalidae, Hesperidae, Pieridae, Lycanidae, Riodinidae, Papilionidae, Castnidae), agrupadas en 18 subfamilias y 67 géneros, dentro de los cuales se encuentran 28 especies catalogadas como endémicas del Chocó Biogeográfico (costa pacífica colombiana), 19 conocidas como especies raras o muy raras y 67 especies comunes para la ciencia (Palacios y Constantino 2006).

\section{Subregión ecogeográfica Litoral Pacífico}

Micay y Timbiquí. La región costera de Micay y Timbiquí fue incluida en la estructura ecológica principal del Chocó Biogeográfico porque, están conformados por una variedad de ecosistemas de importancia ecológica y social, esta variedad de ambientes los faculta para albergar una diversidad de especies que por las presiones antrópicas algunas de estas se encuentran listadas en los libros rojos de Colombia bajo algún grado de amenaza. De acuerdo con los reportes suministrados por INVEMAR, CRC y CORPONARIÑO (2006) esta región alberga 36 especies bajo algún grado de amenaza de todos los grupos fáunicos representativos del Pacífico colombiano incluyendo a especies migratorias como las tortugas que visitan las playas de esta región del país en época reproductiva.

A continuación se presenta el listado de las especies: Leucopteris plumbea (NT), Crax alberti (CR), Penelope perspicax (EN), Camephilus guayaquilensis (NT), 


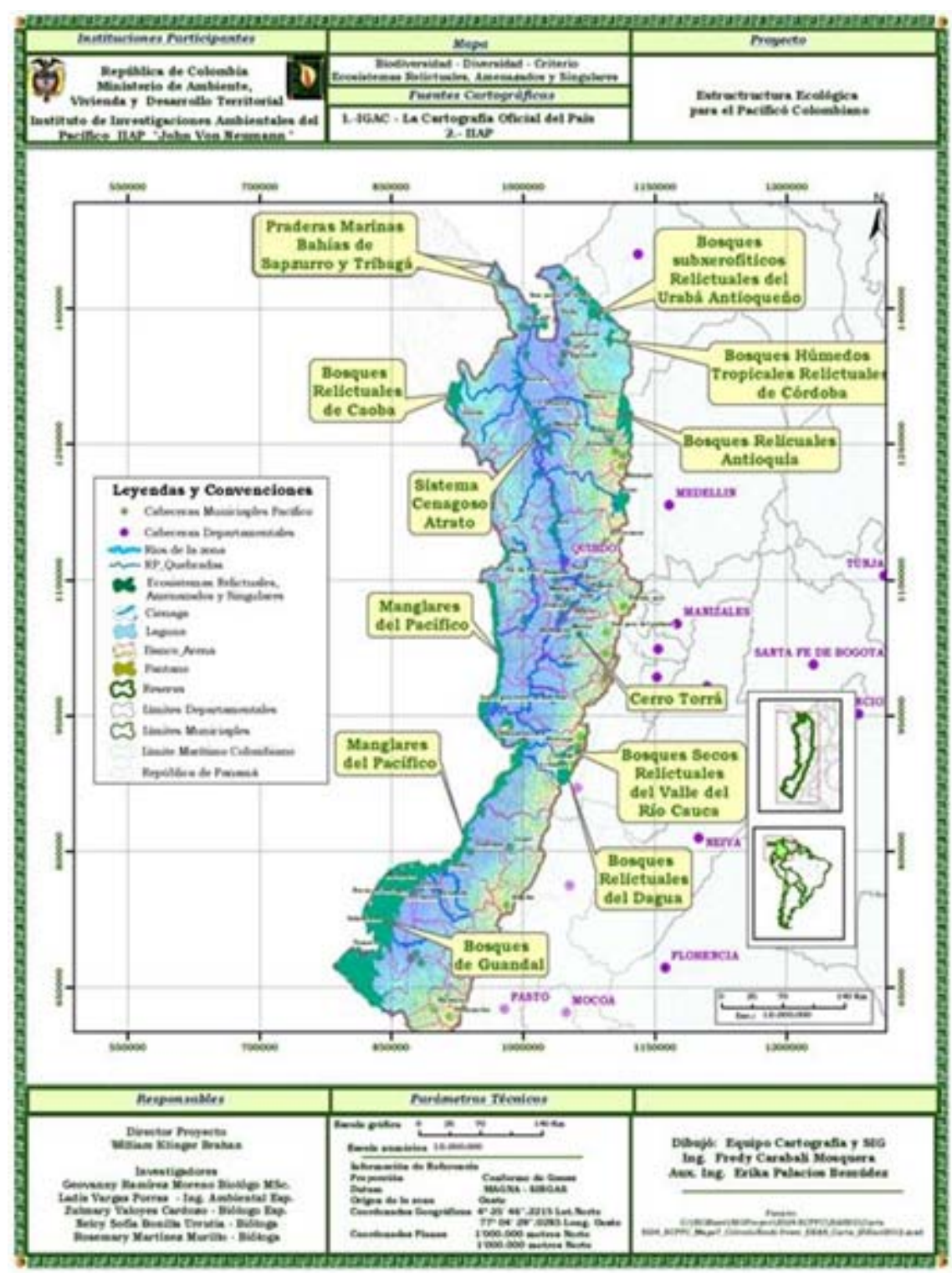

\section{Figura 5. Estructura ecológica principal según subcriterio de ecosistemas relictuales, amenazados y singulares}

Vernilornis chocoensis (NT), Litopenaeus occidentalis (VU), L. vannamei (VU), Aguti paca o Cuniculus (LR), Bradypus variegatus (LR), Alouatta palliata (VU), Cebus capucinus (LR), Mazama americana (LR), Dasyprocta punctata (LR), Choloepus hoffmani (LR), Lutra longicaudis (VU), Myrmecophaga tridactyla (VU), Pecari tajacu (LR), Tayassu pecari (VU), Anadara grandis (VU), A. tuberculosa (VU), Jenneria pustulata (VU), Carcharinus limbatus (VU), Centropomus undecimalis (VU), Cetengraulis mysticetus (VU), Gynglostoma cirratum (VU), Mugil lisa (EN), Pristis pectinata (CR), P. perotteti (CR), Epinephelus itajara (CR), Hippocampus ingens (VU), Caretta caretta (CR), Chelonia agassizii (EN), Ch. mydas (EN), Eretmochelys imbricata (CR), Lepidochelys olivacea (EN), Demorchelys coriacea (CR).
Subcriterio de ecosistemas relictuales, amenazados y singulares

Sitios que por acciones antrópicas se encuentran altamente amenazados y son de importancia para la conservación de especies, congreguan especies de interés amenazada y endémicas; por estas misma acciones solo quedan pequeñas proporciones o son únicos y las especies que se desarrollan en ellos necesiten de estos sitios para su supervivencia, convirtiendo a estas áreas en espacios de gran importancia para la conservación de especies (Figura 5).

\section{Subregión ecogeográfica colinas nororientales}

Bosques húmedos tropicales relictuales de Córdoba. En la actualidad se encuentran fuertemente amenazados; estos fueron remplazados por áreas que hoy son dedicadas a la ganadería, a la agricultura o a la construcción de infraestructura, quedando solo algunos relictos o bastiones de bosque natural sosteniendo a gran parte de la biota que reside en la región la fuerte presión antrópica; estas razones hicieron pertinente la inclusión de estas áreas dentro de la estructura ecológica principal del Chocó Biogeográfico. Los remanentes de bosque natural de Tierralta Córdoba, están ubicados principalmente en la zona amortiguadora del Parque Nacional Natural Paramillo, específicamente en el cerro Murrucucú, bordeando las márgenes del río Sinú en los alrededores de la represa Urrá. El estar localizado en un rango altitudinal que va de 200 a $1200 \mathrm{msnm}$, hace que estos relictos de bosque se constituyan en una amplia variabilidad de hábitats y biotopos que favorecen la presencia de una rica diversidad animal, que incluye muchas especies endémica y amenazada (CVS y CONIF, 2008). 


\section{Subregión ecogeográfica Mulatos}

Corresponde a ambientes de Piedemonte y colinas bajas del norte del Pacífico; es la subregión del grupo con menor humedad disponible (semiseco) y con tipo de roca sedimentaria marina. Se ubica al norte del Pacífico en los municipios de Necoclí, Turbo, Apartadó, Carepa y Chigorodó (Poveda et al. 2004).

Bosques subxerofíticos del Urabá antioqueño. El área representa los últimos bastiones de bosque seco del noroccidente cordobés y antioqueño; estos bosques a través del tiempo han sufrido una gran presión a causa de diferentes acciones antrópicas como la agricultura y ganadería expansiva quedando muy reducido y en estado crítico, razón por la que esta área debe ser incluida en la estructura ecológica principal del Chocó Biogeográfico. Esta área todavía conserva remanentes de bosques naturales, los cuales representan $0.6 \%$ con un área total de $1.823,1$ ha (POT San Pedro de Urabá 1999). Este enclave subxerofítico se encuentra localizado en la región occidental de la Serranía de Abibe, al noroccidente del departamento de Antioquia (Necoclí, San Juan de Urabá, San Pedro de Urabá), estos son prolongación de los bosques secos de Córdoba y hacen parte del bloque Chocó y del terreno Sinú-San Jacinto (Ortega y Montes 2006)

\section{Subregión ecogeográfica Los Saltos}

Esta subregión definida por Poveda et al. (2004) hace parte de las colinas y serranías del Baudó-Darién, la cual comprende tres subregiones, con suelos de formas aluviales y/o lacustres, húmedos de terraza. El tipo de balance hídrico que lo caracteriza es el moderadamente húmedo. Se ubica sobre la serranía de Los Saltos.

Bosques relictuales de Caoba (Swietenia macrophylla). Los bosques relictuales de caoba deben ser incluidos en la estructura ecológica principal del Chocó Biogeográfico porque debido a la intensa explotación maderera durante el último siglo, se redujeron notablemente las poblaciones naturales de Swietenia macrophylla King en más del $80 \%$. Según este criterio (Cárdenas y López 2002) manifiestan que el estado poblacional de esta especie es tan caótico que la definición de lo que fue su distribución original es materia de divagación en los últimos tiempos; en el municipio de Juradó se encuentran relictos de bosque natural de esta importante especie, por lo que se incluyó esta área en la estructura ecológica principal del Chocó Biogeográfico. Las poblaciones naturales de caoba se localizan, a los $355 \mathrm{msnm}$ y 400 msnm respectivamente en la parte alta del municipio, los relictos de caoba se concentran en los bosques primarios de difícil acceso. El estado de las poblaciones es tan lamentable y el uso tan indiscriminado, que esta especie fue incluida en la lista roja de especies maderables amenazadas en la categoría de peligro crítico (Cárdenas y Salinas 2007), además se incluyó en el 2002 en el apéndice II del Cites. A nivel nacional, según este criterio (Cárdenas y López 2002) manifiestan que la Carder, Corpourabá y CDMB han emitido vedas que eviten el aprovechamiento de la caoba, acciones que contribuirán al mantenimiento de la especie. Klinger et al. (2011) manifiestan que las poblaciones de esta especie se encuentran notablemente reducidas, en unárea de $5.8 \mathrm{~h}$ y solo se reportaron la presencia de 16 individuos, presentando el mayor número en estado fustal. Lo anterior pone de manifiesto la presión a que han sido sometidas las poblaciones de esta especie, que se encuentran en declive.

\section{Subregión ecogeográfica central sur}

Bosques secos relictuales del Dagua. El enclave seco del río Dagua, ubicado al occidente sobre la vertiente oriental de la Cordillera Occidental, entre los corregimientos de Loboguerrero y Atuncela, con un microclima muy seco que contrasta con la humedad de su zona de influencia, compuesta por bosques húmedos tropicales, hacen parte del Chocó Biogeográfico y se incluyeron en la estructura ecológica de la región, debido a que actividades como la ganadería, la agricultura, la extracción de leña, los desmontes, quemas y pastoreo han reducido notablemente estos ecosistemas, quedando restringidos a cañadas profundas, desfiladeros y unos cuantos fragmentos. La zona ha sufrido una presión muy fuerte por sus características climáticas, edáficas y la propensión que tienen para ser abiertos por fuego. Hay fuerte actividad agrícola en la zona que tiende a extenderse cada vez más debido a la alta demanda de los productos cultivados (BirdLife International 2011). En la actualidad su cobertura está reducida a no más de 2.400 ha; a pesar de la fuerte presión a que han sido sometidos estos ecosistemas aún cuentan especies y subespecies endémicas, fuertemente amenazadas, por los sistemas productivos intensivos, lo que hace de este ecosistema uno de los más críticos del país (Gómez 2008).

Galindo et al. (2005), manifestaron que este ecosistema para la fecha presentó una cobertura de 7664.45 ha, de las cuales $80.1 \%$ de la cobertura del enclave se encontró transformado respecto a su cobertura original que estaba constituida por bosque seco tropical y matorral xérico, vegetación que ha sido transformada por pastos ( $44.2 \%$ del enclave), cultivos ( $4 \%$ del enclave principalmente caña y piña) y pastizales arbustales con el $20 \%$ del área del enclave. Los ecosistemas transformados ubicados en el piso subandino ocupan $70.5 \%$ (5401.3 ha) del área interpretada y los ecosistemas transformados del piso andino ocupan $6.2 \%$ (475.1 ha). Estos ecosistemas se encuentran destruidos casi en su totalidad y solo quedan algunos fragmentos pequeños en donde está representada la vegetación nativa. A pesar de 


\section{Bioetnia Volumen 9 № 2 (julio-diciembre), 2012}

la importancia ecológica que sustenta este ecosistema los datos suministrados por la CVC (1994-1996 en IAVH 1997), ponen de manifiesto que entre 1957 y 1986, en el valle geográfico del río Cauca hubo una reducción del $66 \%$ de los bosques, y hoy por hoy sólo existe 3\% de la cobertura de la vegetación original, que corresponde sobre todo a bosque seco tropical.

El grupo de plantas más importante en este tipo de cobertura son las cactáceas; se han registrado nueve especies de cactus y dos son endémicos: Melocactus loboguerreroi y Opuntia bella, O. pittieri, Peperomia daguana, Eucharis caucana. Además de las cactáceas, crecen en el sector varias especies de leguminosas arborescentes espinosas, entre las cuales se destacan Acacia pennatula, A. farnesiana Pithecellobium dulce, Zanthoxylon aff. gentryi y la Zanthoxylon fagara. Estas plantas forman en algunos sectores densas marañas, o se concentran en pequeñas colonias donde crecen asociadas con cactus, fique y otras especies de arbustos y hierbas. Otra especie importante en la zona por su endemismo, es Anthurium buenaventurae (BirdLife International 2011). Algunos estudios fáunicos revelan la presencia de 16 especies de herpetofauna y 27 especies de mamíferos, de las cuales 18 son murciélagos y 106 especies de aves, de las cuales se destacan el chococito escarlata (Chrysothlypis salmoni), la pava del Baudó(Penelope ortoni), el carpinterito punteado (Picumnus granadensis), el atrapamoscas apical (Myiarchus apicalis), el batará barrado (Thamnophilus multistriatus) y la tangara rastrojera(Tangara vitriolina). Minyobates bombetes es otra especie endémica para Colombia y se encuentra presente en el bosque seco de Dagua (CVC 2003).

\section{Subregión ecogeográfica litoral del Pacífico}

Mangalares del Pacífico colombiano. Los manglares del Pacífico colombiano se constituyen en uno de los ecosistemas más amenazados del Pacífico colombiano del Chocó Biogeográfico. El IIAP en un análisis de la situación del manglar del Pacífico chocoano, reporta la pérdida de 23.434,5 hectáreas de este importante ecosistema; lo anterior corresponde a una pérdida del $36 \%$ en un período de tan solo 9 años correspondientes a los años 1997 a 2005, lo que equivale a la desaparición 2.603.8 ha/año. De las 41.315,9 hectáreas de manglares reportadas para la región, 17.408.8 hectáreas presentan un alto grado de intervención, 16.505,1 hectáreas tienen grado medio de intervención y 3.460,6 hectáreas presentan un bajo grado de intervención, situación que ubica a los ecosistemas de manglar bajo el criterio de ecosistemas amenazados y por lo tanto deben ser incluidos en la estructura ecológica del Chocó Biogeográfico (IIAP 2010).

\section{Subregión ecogeográfica Bajo Atrato}

Sistemas cenagosos del atrato. Según lo considerado en este criterio (Castellanos 2006) considera que los sistemas cenagosos son más productivos del mundo, en estos se desarrolla una amplia diversidad de flora, fauna y microorganismos que interactúan en complejas relaciones para mantener un equilibrio ecológico de alta fragilidad. Estas condiciones convierten a los sistemas cenagosos del Atrato en ecosistemas singulares que deben ser incluidos en la estructura principal del Chocó Biogeográfico. Estos en términos generales están conformados por un esqueleto vegetal complejo y una vegetación acuática diversa, que se relacionan de manera directa e indirecta con los demás elementos del entorno, jugando un papel fundamental a nivel biológico como productores y permitiendo el establecimiento de una gran variedad de vida clave para el mantenimiento y subsistencia de peces, aves y demás grupos que sobrevienen aquí. La especialización de estos sistemas hacen que se convierta en el único hábitat de un sinnúmero de organismos que habitan allí de forma permanente y el hábitat predilecto de otros que viajan grandes distancias solo para completar un ciclo de su vida (migratorios). A pesar de la dependencia trófica de los organismos, los sistemas completos están regidos por la dinámica hídrica, que los convierte en épocas de inundación y escasez de recursos en un refugio para la biota de los sitios aledaños, dándole un aspecto físico $\mathrm{y}$ biológico diferente cada que se presenta un cambio en esta dinámica.

\section{Subregión ecogeográfica bajo Atrato y litoral del Pacífico}

Ecosistemas de manglar. Los manglares son ecosistemas singulares, de alto valor ecológico, social y cultural. En ellos se crían, alojan y reproducen cientos de especies animales y vegetales; son una fuente de recursos insustituible para numerosas comunidades campesinas que dependen de ellos por lo tanto fueron incluidos en la estructura ecológica principal del Chocó Biogeográfico. En la costa Caribe en lo que corresponde al Chocó Biogeográfico los ecosistemas de manglar se localizan principalmente en la desembocadura del río Atrato en el Golfo de Urabá (Villalba 2008). En la costa pacífica se encuentran altamente representados; estas áreas se diferencia de costa a costa por concentración de precipitaciones. En la costa Atlántica con precipitaciones menores a las de la costa Pacífica, áreas semidesérticas y mareas que no superan los 60 centímetros hacen que las especies de mangle que allí prosperan no superen los $20 \mathrm{~m}$; las especies que predominan este ecosistemas son Avicennia germinans, Conocarpus erectus, Laguncularia racemosa, 
Pelliciera rhizophorae y Rhizophora mangle con una superficie de 41,6 ha (Sánchez-Paéz et al. 2000) y en la costa pacífica alcanzan alturas hasta de $60 \mathrm{~m}$.

\section{Subregión ecogeográfica bajo Patía-Mira}

Bosques de guandal. Los guandales de Nariño fueron incluidos dentro de la estructura ecológica del Chocó Biogeográfico por la complejidad ecológica que alberga, producto de un prolongado proceso de evolución; la especie predominante en este ambiente es Campnosperma pananiensis (sajo). Esta especie crece por lo regular formando masas coetáneas muy homogéneas, constituyendo en la mayoría de los casos más del $80 \%$ de la abundancia relativa por hectárea de estas asociaciones (Del Valle y Galeano, 1995). El aprovechamiento forestal se constituye en una de las principales amenazas a estos ecosistemas.

\section{Subregión ecogeográfica central norte}

Cerro del Torra. El punto que corresponde al cerro del Torrá se encuentra incluida en la estructura ecológica del Chocó Biogeográfico por ser un área que posee ambientes con estructura florística distinta; su condición de bosque nublado hace que sea considerado como uno de los ecosistemas más singulares del mundo (FAO, 2002). Este cerro ha sido catalogado como un páramo sin Espeletia, la familia monotipia Alzateaceae ha sido colectada en Colombia únicamente en este ecosistema; 25,2\% de las plantas vasculares encontradas en este cerro son endémicas de Colombia y 46,9\% está restringida a Centro y Sur América. La flora del Cerro del Torrá es de especial interés porque las colecciones incluyen un porcentaje considerable de especies nuevas. A pesar de que la flora presente en este ecosistema es similar a la encontrada en la región Andina sólo 24,2\% de las plantas vasculares del Torrá han sido encontradas en el cercano Cerro del Inglés. Sin embargo, hay una afinidad fitogeográfica abrumadora con los Andes colombianos. La zona del Torrá conserva, en su mayoría, la cobertura boscosa y es importante porque conforma un cordón montañoso aislado del cuerpo central de la cordillera y a su vez, en su margen occidental empata con la zona plana del Pacífico, dándole un carácter de corredor biológico con la zona andina. En esta zona también se han encontrado especies nuevas de angiospermas, entre las que se destaca la Orquídea de la Paz Epidendrum pazii (Silverstone-Sopkin \&y Ramos-Pérez 1995).

\section{Subregión ecogeográfica Darién-Tacarcuna}

Bahías de Triganá y Sapzurro. Las praderas marinas de Thalassia testudinum (pasto de tortugas) presente en las bahías de Triganá y Sapzurro se incluyó en la estructura ecológica principal del Chocó Biogeográfico, debido a que son consideradas como uno de los cinco ecosistemas marinocosteros más estratégicos del país; hacen parte del único grupo de angiospermas marinas que han evolucionado de tierra firme al mar. Según este criterio (INVEMAR 2000) manifiesta que estos ecosistemas soportan una diversa comunidad de fauna, en donde muchas especies de invertebrados y vertebrados de importancia comercial y ecológica encuentran alimento y sitios de crianza; por otro lado, este ecosistema sirve de alimento a la tortuga verde (Chelonya midas) especie migratoria que pone sus huevos en las playas de esta importante área de la región.

La suma de todos estos factores permiten considerar las praderas marinas de Thalassia testudinum dentro de la estructura ecológica principal de la región, debido a que son uno de los hábitats más afectados, por considerarse frágiles y sensibles, así como por su proximidad a la costa, espacio donde se desarrollan actividades humanas como turismo, construcción de puertos, construcción de obras de infraestructura, etc.

\section{Conclusión}

La estructura ecológica principal del Chocó Biogeográfico teniendo en cuenta el Criterio de Diversidad y Singularidad de Especies y Ecosistemas, está integrada por áreas con altos índices de biodiversidad y ecosistemas estratégicos que se conectan estructural y funcionalmente, permitiendo el desarrollo integral de las comunidades asentadas en el territorio, al mismo tiempo integra sitios que las comunidades han mantenido a través del tiempo y que han sido claves en la construcción de la historia de esta región.

El Chocó Biogeográfico ha sido considerado por muchos autores como uno de los lugares del planeta con mayor diversidad de especies, contiene selvas con los más altos índices de endemismos y especies únicas; esto a su vez propicia la existencia de un sinnúmero de especies y ecosistemas amenazados por acción de las diferentes actividades antrópicas que se han venido practicando en el territorio. Cada una de estas importantes razones permitió conformar una estructura ecológica principal para el Chocó Biogeográfico que abarca un área de 8' 435.552,83 ha, dentro de la cual se incluyeron 36 áreas que sustentan la riqueza de especies y ecosistemas, endemismo, especies y ecosistemas amenazados que la región sustenta.

\section{Literatura citada}

Álvarez-León, R. 2003. Los manglares de Colombia y la recuperación de sus áreas degradadas: revisión bibliográfica y nuevas experiencias. Madera y Bosques 9 (1): 3-25.

Andrade, G. I. 1992. Conservación de la biodiversidad en la provincia 


\section{Bioetnia Volumen 9 № 2 (julio-diciembre), 2012}

biogeográfica chocoana de Colombia una aproximación regional. En: Leyva, P. (ed.). Colombia Pacífico. Tomo II. Proyecto BIOPACIFICO INDERENA, DNP, GEF, PNUD, COL/92/G31. Bogotá: Fondo para la Protección del Medio Ambiente José Celestino Mutis (FEN).

Asprilla, S, Mosquera, A. R., Valoyes, C. M., Cuesta H., García, F. 2003. Composición florística de un bosque Pluvial Tropical (bp-T) en la parcela de investigación en biodiversidad (PPIB) en Salero, Unión Panamericana, Chocó. En la Parcela Permanente de Salero, Unión PanamericanaChocó. En: García, F., Ramos, Y., Palacios, J., Arrollo, J. E., Mena, A., Gonzáles, M. (eds.). Diversidad biológica de un bosque pluvial tropical. Quibdó: Universidad Tecnológica del Chocó, Instituto de Investigaciones Ambientales del Pacifico. Comunidad de Salero.

Armbrecth, I., Armbrecth, H. 1997. Observaciones sobre la variación espacial y temporal de hormigas en un bosque del Chocó colombiano (Arusí). Bol Mus Ent Univ Valle. 5 (2): 15-33.

Betancur, J., García, N. 2006. Las bromelias, las labiadas y las pasiûoras. p. En: García, N., Galeano, G. (eds.). Libro Rojo de Plantas de Colombia. Volumen 3. Bogotá: Instituto Alexander von Humboldt, Instituto de Ciencias Naturales de la Universidad Nacional de Colombia, Ministerio de Ambiente, Vivienda y Desarrollo Territorial.

BirdLife International. 2011. Important bird areas factsheet: Enclave seco del río Dagua. (on 28/12/2011). Downloaded from http://www.birdlife.org

BirdLife International. 2012. Important bird areas factsheet: Delta del río San Juan. (on 13/01/2012). Downloaded from http://www.birdlife.org

Cárdenas-López, D. 2003. Inventario florístico en el cerro del Cuchillo, Tapón del Darién colombiano. Caldasia. 25 (1): 101-17.

Cárdenas, L., Salinas, N. R. (eds.). 2007. Especies maderables Amenazadas: Primera parte. En: Libro rojo de plantas de Colombia. Volumen 4. Bogotá: Instituto Amazónico de Investigaciones Científicas (SINCHI), Ministerio de Ambiente, Vivienda y Desarrollo Territorial. $232 \mathrm{pp}$

Casas, M.O. 2000.http://www.invemar.org/redcosteral/invemar1/docs/ EAMC_2000/INVEMAR_EAMC_2000_06pdf

Cogollo, R., Jaramillo, G. 2005. Estudio de la estructura y diversidad de tres comunidades de árboles en el delta del río San Juan, Chocó, Colombia. Trabajo presentado como requisito para optar al título de Biólogo. Medellín: Instituto de Biología, Facultad de Ciencias Exactas y Naturales Universidad de Antioquia.

Corporación Autónoma Regional de los Valles del Sinú y del San Jorge (CVS) y la Corporación Nacional de Investigación y Fomento Forestal (CONIF). 2008. Formulación del plan general de ordenamiento forestal del departamento de Córdoba (PGOF). Bogotá: CVS, CONIF.

Corporación Autónoma Regional de los Valles del Sinú y del San Jorge (CVS) 2006. Proyecto ordenamiento ambiental terrritorial de la zona amortiguadora del PNN Paramillo, en la Jurisdicción de los municipios de Tierralta, Montelibano y Puerto Libertador, departamento de Córdoba. Bogotá: CVS.

Colorado, A. 2011. El valioso desconocido. Revista el Mueble y la Madera. $\mathrm{http}: / /$ revista-mm.com/ediciones/rev44/art2.htm

Croat, T. 1992. Species diversity of Araceae in Colombia: A preliminary survey. Ann Missouri Bot Gard. 79: 17-28.

Cuesta R, Valencia-Mazo, J. D., Jiménez-Ortega, A. M. 2007. Aprovechamiento de los vertebrados terrestres por una comunidad humana en bosques tropicales (Tutunendo, Chocó, Colombia). Revista Institucional Universidad Tecnológica del Chocó: Investigación Biodiversidad y Desarrollo. 26 (2): 27-43

Corporación Autónoma Regional del Valle del Cauca (CVC). 2003. Identificación de áreas prioritarias para la conservación de cinco ecorregiones en América Latina: GEF/1010-00-14. Ecorregión Chocó, Darién, Panamá, Colombia, Ecuador. Cali: CVC.

Del Valle, J. I. 1996. Los bosques de guandal del delta del río Patía (Colombia). Rev Acad Colomb Cien. 20 (78): 475-89.

Díaz, M. J M. 2006. Bosque seco tropical Colombia. Cali: Banco de Occidente. $205 \mathrm{pp}$.

García-Cárdenas, R. O., Armbrecht, I., Ulloa-Chacón, P. 2001. Staphylinidae (Coleoptera): Composición y mirmecofilia en sosques secos relictuales de Colombia. Folia Enromol Mex. 40 (1): 1-10.

Galindo, G., Cabrera, E., Londoño, C. 2005. Análisis espacial para determinar áreas prioritarias para la conservación de ecosistemas secos en dos valles interandinos del Valle del Cauca, Colombia. Lyonia. 8 (2): 69-83.
Galeano, G. 2002. Estructura, riqueza y composición de plantas leñosas en el golfo de Tribugá, Chocó-Colombia. Caldasia. 23 (11): 2-11.

Galeano, G, Bernal R. 2005. Palmas. Volumen II: palmas, frailejones y zamias. En: Calderón, E., Galeano, G., García, N. (eds). En: Libro Rojo de Plantas de Colombia. Bogotá: Instituto Alexander Von Humboldt, Instituto de Ciencias Naturales, Universidad de Colombia, Ministerio de Ambiente Vivienda y Desarrollo Territorial. pp. 59-223,

Gentry, A. H. 1993. Riqueza de especies y composición florística. Vol. 1. In: Leyva, P. (ed.). Colombia Pacífico. Bogotá: Fondo FEN Colombia. pp. 200-19.

Giraldo, J. A., Del Valle, J. I. 2011. Estudio del crecimiento de Prioria copaifera (Caesalpinaceae) mediante técnicas dendrocronológicas. Rev Biol Trop. 59 (4): 1813-31.

González, H., Gómez, H.D., Arteaga F. 1991. Aspectos estructurales de un bosque de cativo en la región del bajo Atrato, Colombia. Rev Fac Nal Agr. 44: 3-50.

Gómez, N. 2008. Conservación del enclave sub xerofítico del río Dagua, un reto para la comunidad del Valle del Cauca, Colombia. III Congreso Internacional de Ecosistemas Secos. Experiencias y estrategias para su conservación y manejo. Santa Marta, 9-13 de noviembre de 2008, Colombia

Grajales, S. D., Palacios, M. H., Echeverry, C., Gil P. N. 2003. Composición y estructura de una comunidad de Anuros en áreas con diferentes grados de intervención antrópica en Salero, Unión Panamericana, Chocó. En: García, F., Ramos, Y., Palacios, J., Arrollo, J. E., Mena A., Gonzáles, M. (eds.). Diversidad biológica de un bosque pluvial tropical. Quibdó: Universidad Tecnológica del Chocó, Instituto de Investigaciones Ambientales del Pacifico, Comunidad de Salero.

Hernández, J. 1992. Caracterización geográfica de Colombia. En: La diversidad biológica de Iberoamérica. Acta Zool Mex. 1: 45-53.

Instituto Nacional de Vías, Universidad Tecnológica del Chocó. 2005. Estudio de impacto Ambiental y Consulta previa. Conexión terrestre Animas Nuquí. Quibdó: INVIAS, UTCH.

INVEMAR-RC-CORPONARIÑO. 2006. Unidad ambiental costera de la llanura aluvial del sur: caracterización, diagnóstico integrado y zonificación ambiental. López, A. (ed.). Santa Marta: INVEMAR-CRC-CORPONARIÑO. $383 \mathrm{pp}$

Instituto Geográfico Agustín Codazzi (IGAC). 2006. Chocó características geográficas. Bogotá: IGAC. 236 pp.

Instituto de Investigaciones Ambientales del Pacífico y Ministerio del Medio Ambiente Vivienda y Desarrollo Territorial. 2008. Inventario, priorización y caracterización de las ciénagas del municipio del Medio Atrato, Chocó. Quibdó: IIAP, MMAVDT.

Jiménez, A. M., Muñoz, J., Gil, N., González, M., Secaida, M. 2003. Quirópteros, una fauna especial en la parcela permanente de investigación en biodiversidad (PPIB) en Salero, Unión Panamericana, Chocó. En: García, F., Ramos, Y., Palacios, J., Arrollo J. E., Mena, A., González M. (eds). Diversidad biológica de un bosque pluvial tropical. Chocó: Universidad Tecnólogica del Chocó, Instituto de Investigaciones Ambientales del Pacífico, Comunidad Salero.

Klinger, W., Roa, R., Ibarguen, M. T., et al. 2011. Estado de las especies forestales amenazadas. En: Klinger, W., Ramírez, G., Guerra, J. M. 2011. Aportes al conocimiento de los ecosistemas estratégicos y las especies de interés especial del Chocó Biogeográfico. Parte I. Quibdó: Instituto de Investigaciones Ambientales del Pacífico. 168 pp.

Linares, P. R. 1988. Estudio preliminar de la asociación catival en Colombia. Bogotá: Corporación Nacional de Investigación y Fomento Forestal (CONIF).

Machado, M. E., Peña, S, Gil, N. E., Peña, M. J. 2003. Estructura numérica de la comunidad de aves del orden Passeriformes en un bosque con diferentes grados de intervención antrópica en Salero, Unión Panamericana, Chocó. En: García, F., Ramos, Y., Palacios, J., Arrollo, J. E., Mena, A., Gonzáles, M. (eds). Diversidad biológica de un bosque pluvial tropical. Quibdó: Universidad Tecnológica del Chocó, Instituto de Investigaciones Ambientales del Pacifico, Comunidad de Salero.

Mejía, H, Pino, N. B. 2009. Diversidad de orquídeas epífitas en un bosque húmedo tropical (Bh-) del departamento del Chocó. URL disponible en: www.revistas.unal.edu.co/index.php/actabiol/article/.../9377/16903

Mora, M., Bernal, R., Croat, T., Jacomé, J. 2006. A phytogeographic analysis 
of Araceae of Cabo Corrientes (Chocó, Colombia) and comparablel owland tropical American floras. Ann Missouri Bot Gard. 93: 359-66.

Mosquera, L. J., Robledo, D., Asprilla, A. 2006. Diversidad florística de dos zonas de bosque tropical húmedo en el municipio de Alto Baudó, ChocóColombia. Acta Biol Colomb. 12 S: 75-90.

Neita, J. C., Pardo, L. C., Quinto, D., Cuesta N. G. 2003. Los escarabajos copronecrófilos (Coleoptera: Scarabaieidae), en la parcela permanente de investigación en biodiversidad (PPIB) en Salero, Unión Panamericana, Chocó. En: García, F., Ramos, Y., Palacios, J., Arrollo, J. E., Mena, A. y Gonzales, M. (eds.). Diversidad biológica de un bosque pluvial tropical. Quibdó: Universidad Tecnológica del Chocó, Instituto de Investigaciones Ambientales del Pacifico. Comunidad de Salero.

Palacios, M., Constantino, L. M. 2006. Diversidad de lepidópteros Rhopalocera en un gradiente altitudinal en la reserva natural El Pangan, Nariño, Colombia. Boletín Científico - Centro de Museos - Museo de Historia Natural. 10: 258-78.

Palacios, Y., Lloreda, J., Arroyo, J. E., Cogollo, A. 2000. Composición florística de un (bp-T) en la parcela permanente de Salero, Unión Panamericana-Chocó. En: García, F., Ramos, Y., Palacios, J., Arrollo, J. E., Mena, A. y Gonzales, M. (eds.). Diversidad biológica de un bosque pluvial tropical. Quibdó: Universidad Tecnológica del Chocó, Instituto de Investigaciones Ambientales del Pacifico. Comunidad de Salero.

Plan Básico de Ordenamiento Territorial. Municipio San Pedro de Urabá, Antioquia. 1999. http://www.sanpedrodeuraba-antioquia.gov.co/apc-aafiles/POT.pdf

Poveda-M, C., Rojas-P, C. A., Rudas-L1, A., Rangel-Ch., O. 2004. El Chocó Biogeográfico: Ambiente físico. En: Rangel Ch. J. O. (ed.). Colombia Diversidad Biótica IV. El Chocó Biogeográfico/Costa Pacífica. Bogotá: Universidad Nacional de Colombia, Unidad de Monitoreo y ModelajeCBC-Andes-Conservación Internacional.

Proaves 2008. Estudio y conservación del Paujil Piquiazul Crax Alberti. En: Conservación colombiana $N^{\circ}$ 4. Bogotá: PROAVES.

Prieto-C, A., Rudas-L1., A., Rangel-Ch, O., Gónima-G, L., Serrano, H. 2004. La vegetación del Darién colombiano: una aproximación histórica aplicada a la interpretación satelital y videográfica. En: Rangel-Ch., J.O. (ed.), Diversidad biótica IV. El Chocó Biogeográfico/Costa Pacífica.
Bogotá: Universidad Nacional de Colombia, Instituto de Ciencias Naturales, Conservación Internacional. 997 pp.

Ortega, S. C., Montes S. 2006. Bosque seco tropical Colombia. Cali: Banco de Occidente.

Ramírez, M. G., Galeano, G. 2011. Comunidades de palmas en dos bosques de Chocó, Colombia. Caldasia. 33 (2): 315-29.

Ramírez, G. 2011. El Chocó Biogeográfico. En: Klinger, W., Ramírez, G., Guerra, J. M. 2011. Aportes al conocimiento de los ecosistemas estratégicos y las especies de interés especial del Chocó Biogeográfico. Parte I. Quibdó: Instituto de Investigaciones Ambientales del Pacífico. 168 pp.

Ramírez, G., Palacios, L, Klinger W. 2011. Cinco novedades taxonómicas del género Sloanea restringidas a pequeños espacios de la selva pluvial central del Chocó y categorizadas en peligro crítico para Colombia. Bioetnia. 8 (1): 5-15.

Rentería, L. E., Rengifo, J. T., Moya Y. 2007. Comunidad de reptiles presentes en el sotobosque de la selva pluvial central del departamento del Chocó. Revista Institucional Universidad Tecnológica del Chocó: Investigación Biodiversidad y Desarrollo. 26 (2): 23-36.

Robledo, D. 2009. Implementación de estudio base para especies forestales amenazadas, en el municipio de Alto Baudó, departamento del Chocó, Colombia. Bioetnia. 6 (2): 82-92.

Sánchez-Páez, H. G. Ulloa-Delgado, R. Álvarez-León, W. et al. 2000b. Hacia la restauración de los manglares del Caribe de Colombia. SánchezPáez, H., Ulloa-Delgado, G., Álvarez-León R. (eds). Bogotá: MinAmbiente Acofore, OIMT. 350 pp.

The Nature Conservancy (TNC). 2004. The Nature Conservancy contributes to $\$ 11$ million Panama and U.S. debt-for-nature swap. The Nature Conservancy Pressroom.

Villalba, J. C. 2008. Los manglares en el mundo y en Colombia: estudio descriptivo y básico. Bogotá: Sociedad Geográfica de Colombia, Academia de Ciencias Geográficas. 22 pp.

Zambrano-Escamilla, C.H., Rubiano-Rubiano, D.J. 1996. Memoria de los mapas de los bosques de manglar del Pacífico colombiano: 1969, 1996 y multitemporal. Proy. PD 171/91 Rev. 2 (F) Fase I. Inf. Técnico 8. Conservación y manejo para el uso múltiple y el desarrollo de los manglares en Colombia. Bogotá: MINAMBIENTE/OIMT pp.1-41. 